Article

\title{
Rapidly Solidified Gas-Atomized Aluminum Alloys Compared with Conventionally Cast Counterparts: Implications for Cold Spray Materials Consolidation
}

\author{
Bryer C. Sousa ${ }^{1, *(\mathbb{D}, \text { Caitlin Walde }}{ }^{2}$, Victor K. Champagne, Jr. ${ }^{3}$, Aaron T. Nardi ${ }^{3}$, \\ Richard D. Sisson, Jr. ${ }^{1}$ and Danielle L. Cote ${ }^{1, *(D)}$ \\ 1 Materials Science and Engineering, Worcester Polytechnic Institute, Worcester, MA 01609, USA; \\ sisson@wpi.edu \\ 2 Solvus Global, 104 Prescott Street, Worcester, MA 01605, USA; caitlin.walde@solvusglobal.com \\ 3 U.S. Army Research Laboratory, Aberdeen Proving Ground, MD 21005, USA; \\ victor.k.champagne.civ@mail.mil (V.K.C.J.); aaron.t.nardi.civ@mail.mil (A.T.N.) \\ * Correspondence: bcsousa@wpi.edu (B.C.S.); dlcote2@wpi.edu (D.L.C.)
}

Received: 7 September 2020; Accepted: 21 October 2020; Published: 27 October 2020

\begin{abstract}
In this work, three commercially available aluminum alloy systems (Al 2024, Al 6061, and $\mathrm{Al}$ 7075) were considered to explicitly capture the differences in material properties associated with a rapidly solidified, gas-atomized particulate feedstock as compared with their conventionally cast counterparts. Differences between the microstructural, thermodynamic, mechanical, and kinetic behaviors associated with gas-atomized and conventionally bulk counterparts have been tacitly assumed by the cold spray community. However, many researchers continue to utilize legacy properties from bulk materials when simulating particle impact phenomena in silico, for example. By way of recognizing the fact that bulk material properties may not serve as substitutes for gas-atomized powder property input parameters for cold spray process simulation and computation in silico, enhanced cold spray research and development will be more easily achieved. Therefore, understanding the feedstock powder characteristics for use in cold spray can lead to fine-tuning the properties of cold spray consolidations. Optical microscopy, scanning electron microscopy, nanoindentation, microhardness, differential scanning calorimetry, elemental analysis, and cooling rate calculations were utilized. This work confirms preliminary findings that powder alloys may not be treated the same way as their bulk counterparts in so far as the enactment of heat treatment processing parameters are concerned. Specifically, vast discrepancies were found in the grain size, secondary phases, and mechanical behavior between the powder and cast versions of each alloy.
\end{abstract}

Keywords: cold spray; nanoindentation; gas atomization; rapid solidification; light alloys; thermal processing

\section{Introduction}

The production of metallic powders has traditionally been of interest to classical powder metallurgists and research and development engineers alike. Powder metallurgy techniques include hot isostatic pressing, injection molding, and powder forging, among others [1-3]. However, the advent and realization of metal additive manufacturing's potential has enabled a renaissance within the powder production, powder metallurgy, and alloyed powder design communities. Current methods for producing such powders consist of water, gas, and plasma atomization, plasma spheroidization, granulation, sintering-deoxygenation, plasma rotating electrode processing, and more [4]. While each of these methods has their own set of benefits and drawbacks, an almost universal drawback across 
all processes is that the compositions are not optimized for specific processes [5]. Extensive work in the early days of powder metallurgy showed that rapidly solidified powder-based versions of wrought and/or cast counterparts, with equivalent compositions and designations, have refined secondary and primary dendrite arm spacing, extended solid solubility, and a superior combination of strength, toughness, and resistance to corrosion and fatigue upon undergoing powder metallurgy processing [5]. Still, in recent years, the powder-based additive manufacturing community and computational materials scientists alike have come to assume a consistency between bulk material properties and their powder counterparts [6-10].

The solid-state powder-based metal additive manufacturing and materials consolidation technology known as cold gas-dynamic spray, or more simply cold spray, has been used in the aerospace industry and defense sector for repair and reclamation applications, saving time and money over the traditional method of decommissioned part replacement [11]. Cold spray metal additive manufacturing is of growing industrial interest because of the lack of melting associated with the technology, which results in the retainment and refinement of feedstock material properties during processing, among other benefits, such as tuneability as a function of application-specific performance requirements [12]. The feedstock material for these processes is frequently gas-atomized powders [13]. During the gas-atomization process, molten metal is atomized using a gas stream, where the metal rapidly solidifies and is subsequently collected. Rapid solidification results in a generally equiaxed, dendritic, and/or cellular, microstructure that can contain the segregation of alloying elements depending upon the composition of the powder in relation to the gas-atomization parameters utilized. The size and shape of the powder particles are influenced by the alloy composition and the processing parameters utilized during gas atomization as well. For aluminum alloys, the powder particles tend to be primarily spherical in shape, yielding a wide size distribution when produced via gas atomization.

Computational tools can greatly decrease the time required to fully understand cold-spray material consolidation processing and manufacturing, thus decreasing the number of experiments needed to better comprehend the influence of parameters and properties of interest. Accordingly, models have been developed to (1) utilize commercially available thermodynamic and kinetic software, such as Thermo-Calc and Thermo-Calc's DICTRA module (Thermo-Calc Software, Stockholm, Sweden), which uses the chemical composition of the feedstock material, and then (2) couples the outputs associated with (1) with the cold spray consolidation process parameters, such that (3) the output material properties of a consolidated part/component may be derived [14]. The process of integrating feedstock composition with processing parameters and the resultant component performance, by way of taking an in silico approach, has previously been described within the literature as a through-process modeling approach to cold spray materials consolidation and cold spray metal additive manufacturing.

If properties such as strength and toughness are desired outputs of the cold spray through-process model, for example, then similar properties must be input to the model because of the retentive nature of the microstructures and properties associated with cold spray processing. These properties can be obtained from data generated experimentally and/or data gathered from published literature. It is already common practice to gather data on cast/wrought materials through both sources of data; handbooks and decades of experiments provide a significant comparison between literature values and those generated experimentally [15]. Currently, the research community must apply the same approach at a more rapid pace for the accurate modeling of solid-state metal additive manufacturing, especially cold spray, and methods that utilize powders as the feedstock. However, when literature is consulted, there exists a discrepancy between the types of properties reported for alloyed powders and those reported for the same alloys in their respective cast/wrought conditions. Properties such as hardness, strength, melting temperature, and microstructure are reported for cast alloys [16-18], for instance, while properties such as flowability, particle size distribution (PSD), melting temperature, and combustion temperature are more commonly reported and accessible for metallic powders [19-21]. 
To demonstrate the fundamental differences between a material in its bulk condition, as opposed to its gas-atomized state, this paper compares three common aluminum aerospace alloys. More specifically, gas-atomized $\mathrm{Al}$ 2024, $\mathrm{Al}$ 6061, and $\mathrm{Al} 7075$ powders are contrasted against their respective cast counterparts through an analysis of differences in grain size and microstructure, secondary phases, and hardness using optical microscopy, scanning electron microscopy (SEM), dynamic nanoindentation, and microhardness testing. Additionally, differential scanning calorimetry (DSC) analysis was employed for the gas-atomized powders and cast counterparts in their as-manufactured conditions, which enabled secondary phase formation and dissolution kinetics to be explored as a function of material condition. Thereafter, discussion surrounding the implications and immediate consequences of the uniqueness of material properties in the gas-atomized condition are considered in relation to cold spray materials consolidation given the significance of the aforementioned penalties associated with assuming consistency between bulk and atomized properties during particle impact modeling and process parameter optimization, for example.

\section{Methodology}

Gas atomization is known to achieve cooling rates as high as $10^{7}{ }^{\circ} \mathrm{C} \cdot \mathrm{s}^{-1}$ [14]. Since the rate of cooling during gas atomization is orders of magnitude greater than those reported for castings, the classical models relating the microstructure to cooling rates cannot be directly applied to rapidly solidified powders. As such, a relatively simple Newtonian heat transfer model, which was reported by Shiwen et al. [22], was found to be adequate in capturing the mechanisms behind single particle solidification during gas atomization. The simplified heat transfer model for rapidly solidified powders is given in Equation (1), such that

$$
\frac{d T_{d}}{d t}=\frac{12}{\rho C_{p}}\left(T_{d}-T_{g}\right) \frac{k_{g}}{d^{2}}
$$

where $T_{d}$ is the molten metal droplet temperature in ${ }^{\circ} \mathrm{C}, t$ is the time in seconds, $T_{g}$ is the gas atomization temperature in ${ }^{\circ} \mathrm{C}, \rho$ is the droplet density in $\mathrm{kg} \cdot \mathrm{m}^{-3}, \mathrm{C}_{p}$ is the specific heat of the metal droplet in $\mathrm{J} /\left(\mathrm{kg} \cdot{ }^{\circ} \mathrm{C}\right), k_{g}$ is the thermal conductivity of the gaseous species utilized during gas atomization in $\mathrm{W} /\left(\mathrm{m} \cdot{ }^{\circ} \mathrm{C}\right)$, and $d$ is the droplet diameter in meters.

Inspection of Equation (1) reveals the fact that the cooling rate is inversely proportional to the droplet diameter, as shown in Equation (2), such that

$$
\frac{d T_{d}}{d t} \propto d^{-2}
$$

Table 1 tabulates $\rho, T_{d}$, and $C_{p}$ for each of the aluminum alloys studied herein. Since the powders provided by Valimet, Inc. (Stockton, CA, USA), were gas-atomized in $\mathrm{N}_{2}$ gas, the $k_{g}$ was $0.024 \mathrm{~W} /\left(\mathrm{m} \cdot{ }^{\circ} \mathrm{C}\right.$ ), while the $T_{g}$ was $26.85^{\circ} \mathrm{C}$ for cooling rate calculations.

Table 1. Droplet density, molten metal droplet temperature, and specific heat associated with the rapidly solidified aluminum alloys considered herein: Al 2024, Al 6061, and Al 7075.

\begin{tabular}{cccc}
\hline Alloy & Droplet Density $\left(\mathbf{k g} \cdot \mathbf{m}^{-3}\right)$ & Molten Metal Droplet Temperature $\left({ }^{\circ} \mathbf{C}\right)$ & Specific Heat $\left(\mathrm{J} /\left(\mathbf{k g} \cdot{ }^{\circ} \mathbf{C}\right)\right)$ \\
\hline A1 2024 & 2270 & 1200 & 1140 \\
\hline Al $\mathbf{6 0 6 1}$ & 2700 & 1200 & 896 \\
\hline Al 7075 & 2810 & 1200 & 960 \\
\hline
\end{tabular}

In casting or solidification metallurgy, there is a proven relationship between secondary dendrite arm spacing $\left(\lambda_{x}\right)$ and solidification cooling rate, as given in Equation (3), such that

$$
\lambda_{x}=\lambda_{o_{x}}\left(\frac{d T}{d t}\right)^{-n}
$$


wherein $\lambda_{o_{x}}$ and $n$ are alloy-dependent constants, $n$ is a unitless exponent, and $\lambda_{o_{x}}$ is expressed in units of length. The materials property simulation software JMatPro (Sente Software, Guildford, UK; Version 9.1.1) was used to determine the value of $\lambda_{o_{x}}$ for $\mathrm{Al}$ 2024, $\mathrm{Al}$ 6061, and $\mathrm{Al}$ 7075. Accordingly, $\lambda_{0_{2024}}$ was found to be 86.741 , while $\lambda_{0_{6061}}$ was found to be 99.853 , and $\lambda_{07075}$ was found to be 90.049 . A value of 0.33 was used for $n$ for all of the aluminum alloys.

To relate the powder particle cooling rates with their microstructural sub-grain size, which behaves as an effective grain size for rapidly solidified polycrystalline aluminum powders, Equations (1) and (3) were combined, resulting in the relationship given in Equation (4), such that

$$
\lambda_{x}=\lambda_{o_{x}}\left(\frac{12}{\rho C_{p}}\left(T_{d}-T_{g}\right) \frac{k_{g}}{d^{2}}\right)^{-n}
$$

With respect to the alloys in their cast conditions, thermocouples were used to experimentally determine the cooling rates experienced upon solidification during the casting process. According to Ghoncheh et al. [23], the relationship between dendrite arm spacing (DAS) and cooling rate for cast $\mathrm{Al} 2024$ is given in Equation (5), such that

$$
D A S=46.51\left(\frac{d T}{d t}\right)^{-0.59}
$$

and DAS is in $\mu \mathrm{m}$. In the case of $\mathrm{Al} 6061$ and $\mathrm{Al}$ 7075, the DAS relation given in Equation (6) is a reasonable approximation [23], such that

$$
D A S=45.00\left(\frac{d T}{d t}\right)^{-0.39}
$$

For the cast samples, $\mathrm{Al} 2024, \mathrm{Al} 6061$, and $\mathrm{Al} 7075$ were purchased as sheets, subsequently melted, and cast in-house into cylinders with $28 \mathrm{~mm}$ diameters. The cooling rates were measured in the center of the cylinder. Optical emission spectrometry (OES) was used to measure the compositions of the three as-cast alloys. The OES device was made by SPECTRO Analytical Instruments (Kleve, Germany).

As previously mentioned, each of the alloyed aluminum powders was gas-atomized in nitrogen by Valimet, Inc. The cooling rate during this process was in the order of $10^{4}-10^{5}{ }^{\circ} \mathrm{C} \cdot \mathrm{s}^{-1}$. The as-atomized powders were mechanically sieved from the initial PSD to the studied ranges, with $\mathrm{D}_{10^{\prime}} \mathrm{s}, \mathrm{D}_{50^{\prime}} \mathrm{s}$, and $\mathrm{D}_{90^{\prime}} \mathrm{s}$ shown Table 2. In statistical terms, $\mathrm{D}_{10}$ signifies that $10 \%$ of the particles are smaller than this value and so on for $\mathrm{D}_{50}$ and $\mathrm{D}_{90}$. The compositions of the powders were evaluated using direct current plasma emission spectroscopy as performed by Luvak Laboratories, Inc. (Boylston, MA, USA).

Table 2. Powder size distribution-related values associated with the rapidly solidified aluminum alloys considered herein: Al 2024, Al 6061, and Al 7075.

\begin{tabular}{cccc}
\hline Alloy & $D_{\mathbf{1 0}}(\mu \mathrm{m})$ & $D_{\mathbf{5 0}}(\mu \mathrm{m})$ & $D_{\mathbf{9 0}}(\mu \mathrm{m})$ \\
\hline Al 2024 & 18.5 & 34.2 & 57.8 \\
\hline Al 6061 & 33.8 & 41.2 & 54.3 \\
\hline Al 7075 & 26.1 & 37.1 & 52.9 \\
\hline
\end{tabular}

Thermal processing was performed on one set of samples at a time in the DSC, since the DSC maintains highly accurate temperature control. One set of samples for each alloy was left untreated in their as-solidified conditions as controls. Cast samples were cut to fit into DSC crucibles, with two parallel flat sides. Heat treatments were performed using a heating rate of $50{ }^{\circ} \mathrm{C} \cdot \mathrm{min}^{-1}$ and a cooling rate of $120^{\circ} \mathrm{C} \cdot \mathrm{min}^{-1}$. Samples were brought to the thermal treatment temperature determined for each alloy $\left(490{ }^{\circ} \mathrm{C}\right.$ for $\mathrm{Al} \mathrm{2024,530}{ }^{\circ} \mathrm{C}$ for $\mathrm{Al} 6061$, and $480{ }^{\circ} \mathrm{C}$ for $\mathrm{Al} \mathrm{7075)}$ ) and held for $1 \mathrm{~h}$ before being quenched. Nitrogen was used as the purge gas. Specifically, a TA Instruments (New Castle, $\mathrm{DE}, \mathrm{USA}$ ) Discovery DSC with an $\mathrm{LN}_{2} \mathrm{P}$ cooler was used. DSC thermograms of the gas-atomized and 
as-cast samples were generated at a heating rate of $5{ }^{\circ} \mathrm{C} \cdot \mathrm{min}^{-1}$ in a nitrogen environment. As will be discussed hereafter, the composition of the cast $\mathrm{Al} 2024$ specimens, which was obtained via OES analysis, was outside of the specified limits for the alloy.

The grain/sub-grain size for each of the samples was characterized via etching and subsequent optical microscopy. For etching, samples were compression mounted in a phenolic resin and then ground and polished with a final $0.05 \mu \mathrm{m}$ colloidal silica suspension step. Once polished to a mirror finish, the samples were etched using the reagents and times described in Table 3.

Table 3. Chemical etching reagents and etching times for each of the conventionally cast as well as rapidly solidified aluminum alloys considered herein: Al 2024, Al 6061, and Al 7075.

\begin{tabular}{|c|c|c|c|}
\hline \multirow{2}{*}{ Al Alloy } & \multirow{2}{*}{ Etching Reagent } & \multicolumn{2}{|c|}{ Etching Time (seconds) } \\
\hline & & Powder & Cast \\
\hline Al 2024 & $\begin{array}{l}\text { Keller's Reagent }(1.0 \% \text { hydrofluoric }(\mathrm{HF}) \\
\text { acid, } 1.5 \% \text { hydrochloric acid, } 2.5 \% \text { nitric } \\
\left.\text { acid, and } 95.0 \% \text { distilled } \mathrm{H}_{2} \mathrm{O}\right)\end{array}$ & 5 & 35 \\
\hline Al 6061 & $0.5 \% \mathrm{HF}$ acid; $99.5 \%$ distilled $\mathrm{H}_{2} \mathrm{O}$ & 60 & 120 \\
\hline Al 7075 & Keller's Reagent (see Al 2024 row) & 5 & 17 \\
\hline
\end{tabular}

Then, microstructural sizes were measured using optical micrographs and Olympus Stream's software package for grains and intercepts (Olympus Corporation, Shinjuku City, Tokyo, Japan). To reduce the distortion due to the local curvature on the edge of the polished powder particle cross-sections, only features near the center of the front face of the powders were included in the measurements. Due to the contribution of the $\lambda_{x}$ in relation to the measurements, grains were measured in a comparable method: from the center of the grain boundaries to the center of the grain.

Samples were prepared for SEM the same way they were prepared for etching. SEM micrographs were taken using a tungsten-filament-source SEM (EVO MA-10, Carl Zeiss Microscopy, Thornwood, NY, USA). Both secondary electron and backscattered electron micrographs were taken. The backscattered electron micrographs were used to evaluate the number of secondary phases present in each condition. This was accomplished by way of contrast thresholding using image analysis software. Previous work was referenced to correlate the appearance of secondary phases to their stoichiometries [24-26]. The diffraction pattern obtained from scanning transmission electron microscopy analysis of a dark phase within an $\mathrm{Al} 6061$ gas-atomized particle was performed to validate the prior works referenced as well.

Nanoindentation testing was performed using an iMicro Pro system from Nanomechanics, Inc. (Oakridge, TN, USA), which is now part of KLA Instruments (KLA Corporation, Milpitas, CA, USA), on the metallographically prepared powder samples. The InForce $50 \mathrm{mN}$ actuator was employed with a diamond Berkovich tip from Micro Star Technologies Inc. (Huntsville, TX, USA). In total, 25 particles were selected for nanoindentation testing per sample. Nanoindentation hardness measurements were reported at depths of $250 \mathrm{~nm}$ using the advanced dynamic hardness and modulus method provided by Nanomechanics, Inc. Using standard methods, the tip was cleaned, and the contact area function was analytically determined via analysis of the load-depth data from a fused silica sample. Thermal drift, pile-up, and creep-related phenomena were corrected for during testing. For additional information regarding the application of nanoindentation testing to particulate feedstock for cold spray, one may consider the work of Sousa et al. in [27].

Microhardness testing of the cast samples was performed with a DiaMet Hardness Tester from Buehler (Lake Bluff, IL, USA). The microhardness data were collected using a Vickers indenter tip and an applied force of 0.1 kilogram-force (kgf). Since the Vickers and Berkovich tip geometries have essentially the same contact area and also result in similar strains during indentation, the nanoindentation hardness 
$\left(H_{N I}\right)$, in units of $\mathrm{MPa}$, was readily converted to a Vickers Hardness Number (VHN) via Equation (7), such that

$$
H V N=0.0945 * H_{N I}
$$

Therefore, the nanoindentation hardness's were directly converted to a VHN for direct comparison with the microhardness responses associated with the cast counterparts. For the purpose of comparison, note that the load required to achieve an indentation depth of $250 \mathrm{~nm}$ during nanoindentation of the gas-atomized alloyed powders studied herein was only $0.000254929 \mathrm{kgf}$ versus the $0.1 \mathrm{kgf}$ applied during microindentation testing.

\section{Results}

The temperature of the three conventionally cast alloyed aluminum counterparts as a function of time was determined as shown in Figure 1. Interestingly, Figure 1 captures various intersectional points along the three temperature-time curves, wherein alloy-specific curves are found to change course relative to one another. Said otherwise, $\mathrm{Al} 6061$ and $\mathrm{Al} 7075$ initially appeared to experience a more rapid rate of change in temperature as function of time than that of $\mathrm{Al} 2024$. However, inspection of the intersections between two curves along the two-dimensional plot suggests that $\mathrm{Al} 2024$ eventually achieves and retains a greater cooling rate as a function of time than that of $\mathrm{Al} 6061$ and $\mathrm{Al} \mathrm{7075,}$ for example.

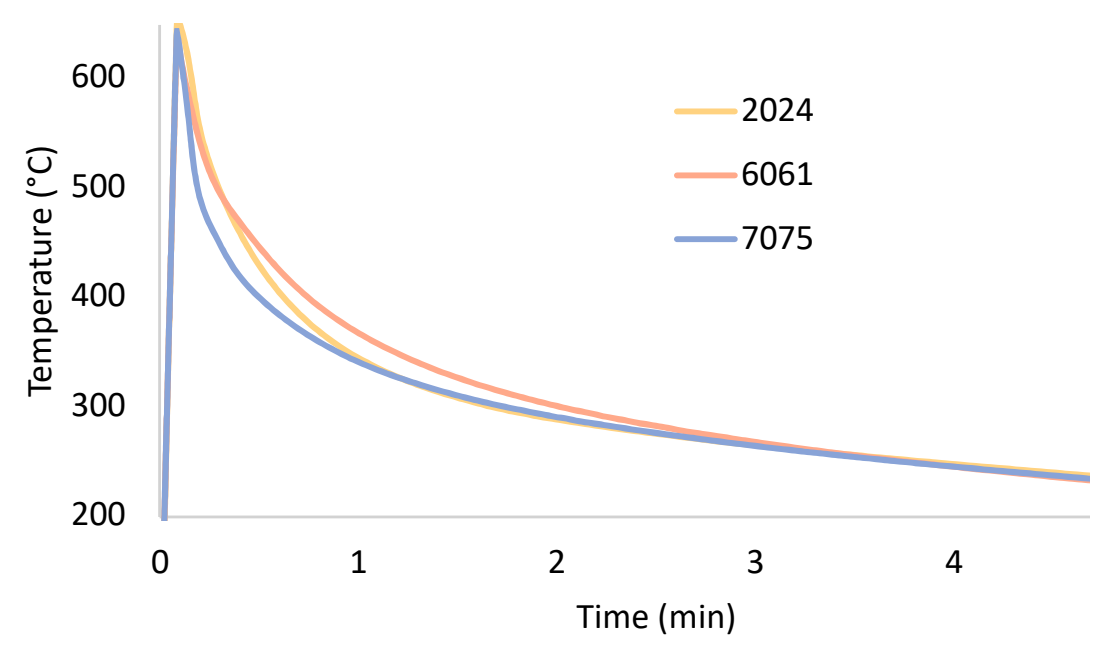

Figure 1. Temperature as a function of time for each alloy during casting.

Considering the depiction of temperature as a function of time for the three conventionally cast alloyed aluminum counterparts, as shown in Figure 1, the associated cooling rates as a function of time between 6 and $30 \mathrm{~s}$ are given next. Accordingly, the experimentally measured cooling rates for cast $\mathrm{Al} 2024, \mathrm{Al}$ 6061, and $\mathrm{Al} 7075$, which were obtained by way of the use of the thermocouples described in the Methodology section, are shown in Figure 2. The aforementioned inspection of the temperature-time curves presented in Figures 1 and 2 enabled the actual cooling rates as a function of time to be evaluated. The $\mathrm{Al} 6061$ and $\mathrm{Al} 7075$ castings initially achieved greater cooling rates as a function of time. As expected, $\mathrm{Al} 2024$ eventually surpasses the discrete cooling rate values at equivalent points in time that follow $\mathrm{Al} 2024$ 's measured cooling rate versus time curve intersections with $\mathrm{Al} 6061$ and $\mathrm{Al} 7075$. 


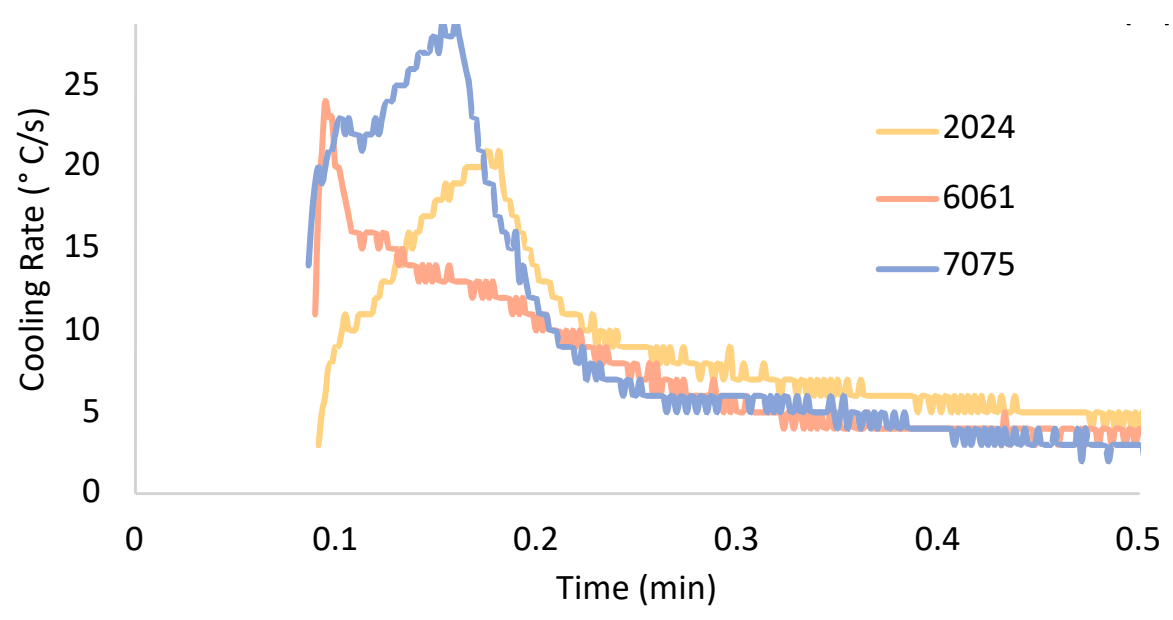

Figure 2. Cooling rate as a function of time for each alloy during casting.

Figure 2 also revealed the fact that $\mathrm{Al}$ 2024's curve intersects Al 6061's curve before intersecting Al 7075's curve. The curves associated with $\mathrm{Al} 6061$ and $\mathrm{Al} 7075$ also experienced at least two points at which the curves intersected one another. However, within the range of time associated with Figure 2, as can be found along the horizontal axis of the cooling rate versus time plot, Al 2024 only intersected each of the two other curves one time. As for the peak cooling rates achieved for each of the three curves given in Figure 2, Al 7075 achieved the greatest cooling rate during solidification upon casting, which was followed by Al 6061 and then $\mathrm{Al} 2024$. Still, Al 6061 reached its maximal casting cooling rate before $\mathrm{Al} \mathrm{7075,} \mathrm{while} \mathrm{both} \mathrm{Al} 6061$ and $\mathrm{Al} 7075$ reached their peak cooling rates before $\mathrm{Al} 2024$. Finally, the difference between the maximum and minimum cooling rates as a function of time for each alloy designation considered herein could be organized from greatest to lowest as follows: Al 7075, $\mathrm{Al}$ 6061, followed by Al 2024.

Having presented temperature-time curves (see Figure 1) as well as cooling rate versus time curves (see Figure 2) for the conventionally cast Al 2024, Al 6061, and Al 7075 bulk material counterparts, the cooling rates associated with the gas-atomized powders were ascertained as a function of particle diameter for each of the gas-atomized alloys considered, as shown in Figure 3c. At the same time, Figure $3 a, b, d$ presents the experimentally measured as well as calculated effective grain sizes as a function of particle size for $\mathrm{Al}$ 2024, $\mathrm{Al}$ 6061, and Al 7075, respectively. The effective cooling rate versus particle diameter function (recall Equation (4)) was used to calculate the effective grain size for each alloy. Appreciable agreement between the grain size calculations (solid line in Figure $3 a, b, d$ ) and the experimentally measured grain sizes (data points in Figure 3a,b,d) was observed.

From Figure 3c, one may note that the calculated cooling rates as a function of particle diameter for each of the gas-atomized systems considered during the course of this work were similar to one another. Figure $3 \mathrm{c}$ also enabled the visualization of consequences associated with the inverse proportionality between molten metal droplet diameter and cooling rate, which was mathematically expressed in Equation (2) upon inspection of the simplified heat transfer model for the rapidly solidified powders presented in Equation (1). A detailed consideration of Figure 3c also identified gas-atomized Al 6061 as the rapidly solidified alloy with the greatest cooling rate for a given particle size, followed by $\mathrm{Al}$ 7075 and $\mathrm{Al} 2024$, in that order. 
7075
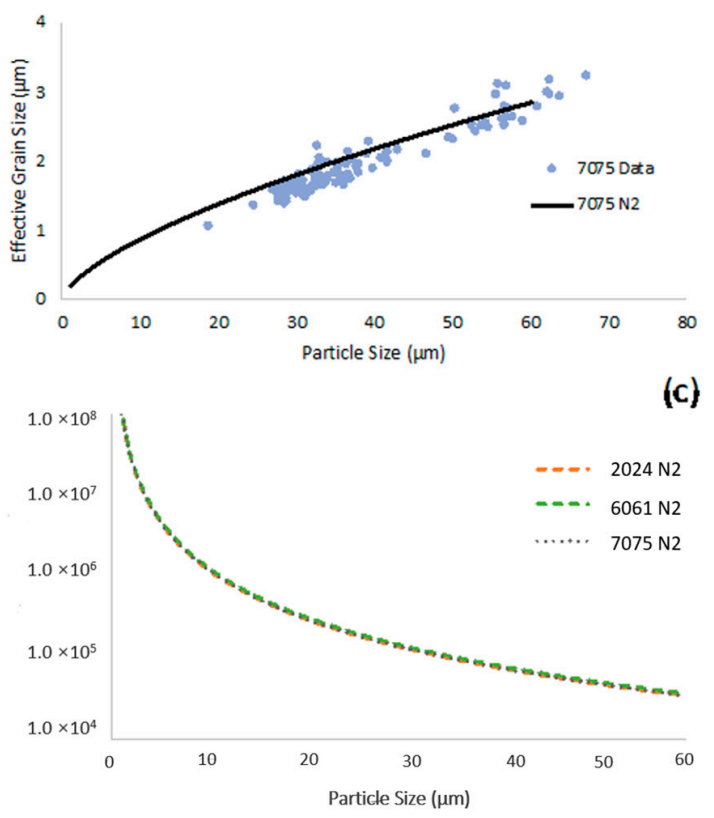

(c)

(a)

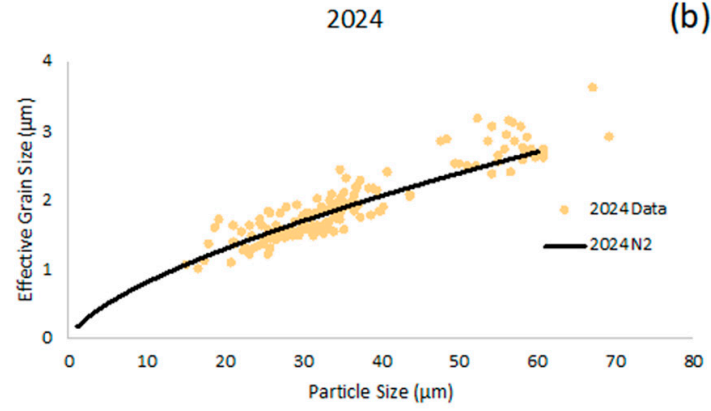

(d)

(b)

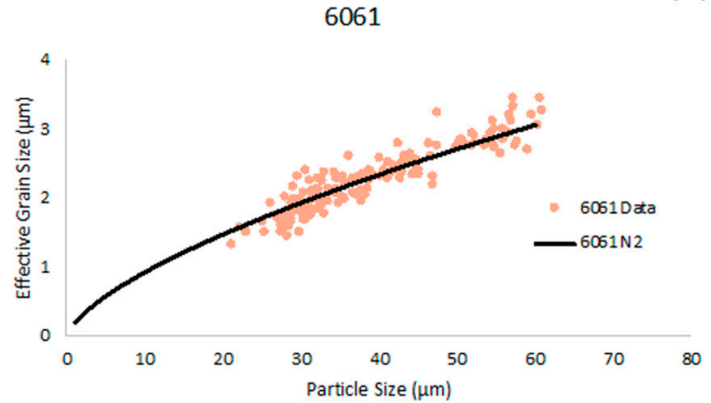

Figure 3. Grain size as a function of particle size, both predicted/theoretical and experimental, for the three alloys studied in the as-atomized state. (a) depicts the calculated and experimentally measured Al 7075 gas-atomized powder particle grain sizes as a function of particle size. The same analysis was presented in (b,d) for gas-atomized Al 2024 and Al 6061, respectively. Finally, (c) presents the calculated cooling rates as a function of particle size for each of the gas-atomized aluminum alloys studied herein.

Given the fact that the curves presented within Figure 3c followed from the use of Equation (1) as well as the fact that secondary dendrite arm spacing was formulated as a function of the solidification cooling rate in Equation (3), the substitution of Equation (1) into Equation (3) enabled powder particle cooling rates to be expressed in relation to their microstructural effective grain size, as shown in Equation (4); Figure 3c can be linked with Figure 3a,b,d. Mathematical manipulation of the computed cooling rates and calculated microstructural effective grain sizes enabled the effective grain size as a function of powder particle size to be calculated for Al 7075, Al 2024, and Al 6061, as shown in Figure $3 a, b, d$, respectively, in the form of continuous black curves. Then, the experimentally measured effective grain sizes as a function of particle size for the three rapidly solidified aluminum alloys in the as-atomized state were able to be directly captured by way of plotting the calculated curves alongside the measured data points in Figure $3 a, b, d$.

Analysis of Figure 3a,b,d appears to suggest that Al 6061's calculated effective grain size as a function of particle size was the most consistent with experimentally measured findings and observations, followed by Al 2024 and Al 7075 in that order. As shown in Figure 3a, the Al 7075 calculations over-estimated the effective grain size as a function of particle size when compared with the corresponding experimental data. On the other hand, the Al 2024 computed curve trajectory was reasonably consistent with the experimentally measured values until surpassing a particle diameter of approximately $45 \mu \mathrm{m}$.

Transitioning from cooling rate calculations and analysis toward kinetic behavior and compositions, the experimentally derived chemistries of the gas-atomized powders as well as the as-cast samples are compared to the standard compositional ranges defined by ASM International in Figure 4 [24,28]. As will be discussed, the copper, chromium, manganese, and magnesium weight percentages obtained from the cast Al 2024 sample nullifies its ability to be defined as non-nominal Al 2024. As for Al 6061, the magnesium weight percent associated with the cast counterpart was less than the lower limit associated with the alloys' compositional range. As for gas-atomized Al 6061, the manganese content 
was shown to be greater than the upper limit provided by ASM International. Regarding Al 7075, the zinc weight percent for the cast counterpart was found to be shy of the lower limit prescribed by ASM International, too.

\begin{tabular}{|c|c|c|c|}
\hline \multirow{2}{*}{ Element } & \multicolumn{3}{|c|}{ Al 2024 } \\
\cline { 2 - 4 } & Cast & ASM & Powder \\
\hline $\mathbf{C r}$ & 0.197 & $<0.10$ & 0.0051 \\
\hline $\mathbf{C u}$ & 0.012 & $3.80-4.90$ & 3.83 \\
\hline $\mathbf{F e}$ & 0.291 & $<0.50$ & 0.065 \\
\hline $\mathbf{M g}$ & 2.25 & $1.20-1.80$ & 1.51 \\
\hline $\mathbf{M n}$ & 0.06 & $0.30-0.90$ & 0.54 \\
\hline $\mathbf{S i}$ & 0.142 & $<0.50$ & 0.13 \\
\hline $\mathbf{T i}$ & 0.011 & $<0.15$ & 0.0029 \\
\hline $\mathbf{Z n}$ & $<0.001$ & $<0.25$ & 0.013 \\
\hline $\mathbf{A l}$ & 97.00 & Bal. & 93.904 \\
\hline
\end{tabular}

\begin{tabular}{|c|c|c|c|}
\hline \multirow{2}{*}{ Element } & \multicolumn{3}{|c|}{ Al 6061 } \\
\cline { 2 - 4 } & Cast & ASM & Powder \\
\hline $\mathbf{C r}$ & 0.19 & $0.04-0.35$ & 0.087 \\
\hline $\mathbf{C u}$ & 0.164 & $0.15-0.4$ & 0.25 \\
\hline $\mathbf{F e}$ & 0.373 & $<0.7$ & 0.27 \\
\hline $\mathbf{M g}$ & 0.66 & $0.8-1.2$ & 0.95 \\
\hline $\mathbf{M n}$ & 0.06 & $<0.15$ & 0.34 \\
\hline $\mathbf{S i}$ & 0.52 & $0.4-0.8$ & 0.49 \\
\hline $\mathbf{T i}$ & 0.019 & $<0.15$ & 0.024 \\
\hline $\mathbf{Z n}$ & 0.024 & $<0.25$ & 0.035 \\
\hline $\mathbf{A l}$ & 98.00 & Bal. & 97.554 \\
\hline
\end{tabular}

\begin{tabular}{|c|c|c|c|}
\hline \multirow{2}{*}{ Element } & \multicolumn{3}{|c|}{ Al 7075 } \\
\cline { 2 - 4 } & Cast & ASM & Powder \\
\hline $\mathbf{C r}$ & 0.201 & $0.18-0.28$ & 0.20 \\
\hline $\mathbf{C u}$ & 1.36 & $1.2-2.0$ & 1.59 \\
\hline $\mathbf{F e}$ & 0.151 & $<0.5$ & 0.17 \\
\hline $\mathbf{M g}$ & 2.21 & $2.1-2.9$ & 2.50 \\
\hline $\mathbf{M n}$ & 0.027 & $<0.3$ & 0.26 \\
\hline $\mathbf{S i}$ & 0.059 & $<0.4$ & 0.15 \\
\hline $\mathbf{T i}$ & 0.03 & $<0.2$ & 0.029 \\
\hline $\mathbf{Z n}$ & 4.94 & $5.1-6.1$ & 5.71 \\
\hline $\mathbf{A l}$ & 91.022 & Bal. & 89.391 \\
\hline
\end{tabular}

Figure 4. Experimentally derived chemistries of the gas-atomized powders as well as the as-cast samples compared to the standard compositional ranges defined by ASM International for each of the three systems studied herein: Al 2024, Al 6061, and Al 7075.

Normalized DSC-based heat flow versus temperature thermograms were obtained for both the nominally cast Al 2024 counterpart as well as the gas-atomized Al 2024 powder as shown in Figure 5. Considering the fact that Figure 4 demonstrated the fact that so many of the alloying elements associated with Al 2024 in the cast condition were either above or below the ASM International specified thresholds, the lack of secondary phase activity captured for the as-cast condition was not surprising. While the as-cast heat flow versus temperature curve revealed little to no activity between 50 and $200{ }^{\circ} \mathrm{C}$, the gas-atomized $\mathrm{Al} 2024$ DSC scan revealed a peak local maximum at a temperature of about $100{ }^{\circ} \mathrm{C}$. The non-negative nature of the local maxima suggests secondary phase formation activity in the gas-atomized Al 2024. Clearly, such activity was absent from the data associated with the cast counterpart.

Al 2024

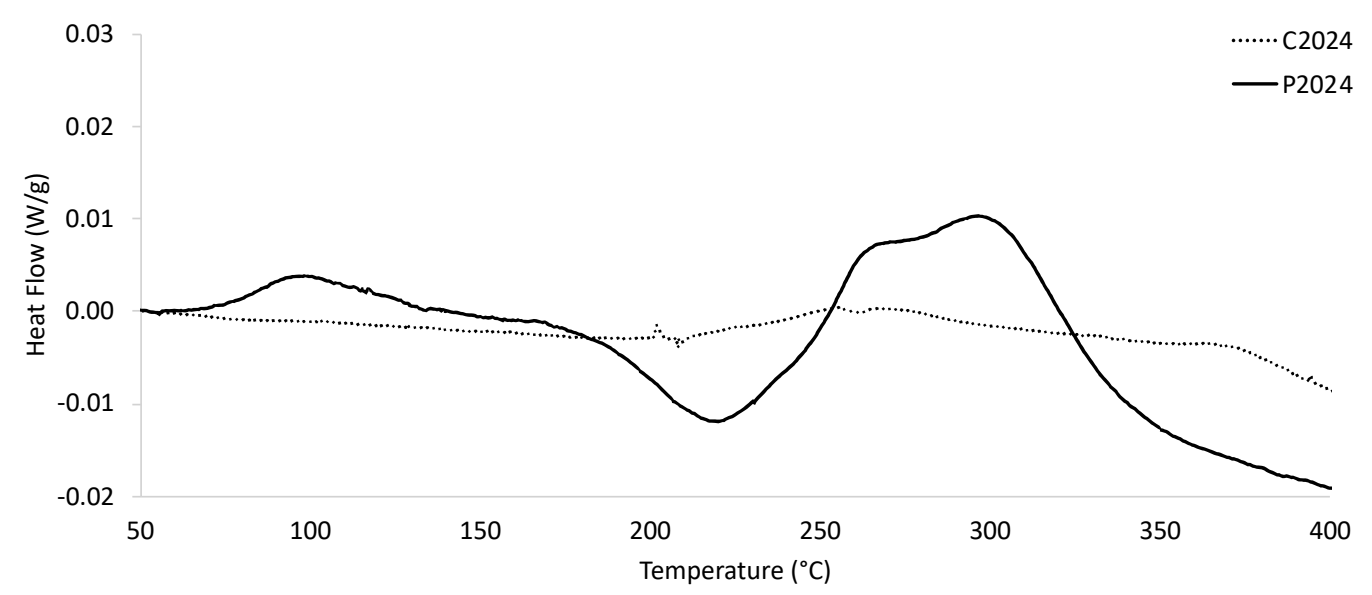

Figure 5. Differential scanning calorimetry-derived heat flow versus temperature curves for the as-cast as well as the as-atomized Al 2024 materials.

Following the initial local maximum identified in Figure 5, another local minimum was observed around a temperature of approximately $220{ }^{\circ} \mathrm{C}$ for the gas-atomized $\mathrm{Al} 2024$ powder. While discontinuities were also observed in the as-cast Al 2024 counterpart that were between approximately 210 and $240{ }^{\circ} \mathrm{C}$, the magnitude of the blip prevents immediate and definitive conclusions from being drawn in terms of secondary phase formation and/or dissolution. That being said, the bimodal local maxima and activity in the cast $\mathrm{Al} 2024$ specimen DSC data between 250 and $275^{\circ} \mathrm{C}$ 
warrants prospective consideration. Whilst the dual local maxima between 250 and $275^{\circ} \mathrm{C}$ in the cast $\mathrm{Al} 2024$ were virtually equal in magnitude with one another, the two locally convoluted peaks in the gas-atomized $\mathrm{Al} 2024$ condition were clearly differentiable from one another, with the peak associated with a temperature of at least $260^{\circ} \mathrm{C}$ being slightly less than that of its subsequent peak around a temperature of $300^{\circ} \mathrm{C}$ or so.

Considering the temperatures associated with said bimodal local peaks, the peaks associated with the gas-atomized powder were shifted to the right relative to the casting's temperature-based location within the curve. While the DSC curve for the cast condition presented in Figure 5 between 275 and $400{ }^{\circ} \mathrm{C}$ appeared to partially plateau before decreasing after a temperature of $360{ }^{\circ} \mathrm{C}$ was crossed, the gas-atomized Al 2024 DSC curve continuously decreased immediately following the onset of the bimodal local maxima.

Figure 6 presents another pair of DSC-derived heat flow versus temperature curves, which were obtained by way of considering the gas-atomized and conventionally cast Al 6061 specimens. The thermogram presenting the heat flow versus temperature behavior of the gas-atomized $\mathrm{Al} 6061$ as well as the as-cast $\mathrm{Al} 6061$ in Figure 6 were normalized prior to being presented graphically. Unlike the thermogram and data associated with the rapidly solidified Al 2024 and Al 2024 casting, which were both presented in Figure 5, the DSC curves associated with both the gas-atomized Al 6061 and traditionally solidified Al 6061 specimens were remarkably similar with each other. While the two $\mathrm{Al} 6061$ heat flow versus temperature curves take on similar shapes relative to each other, the data begin to no longer share near one-to-one coordinates after $200{ }^{\circ} \mathrm{C}$ or so. Nevertheless, the widely distributed or broad peaks associated with both $\mathrm{Al} 6061$ curves between 250 and $300{ }^{\circ} \mathrm{C}$ with respect to the $x$-axis were self-similar. After a temperature of $300{ }^{\circ} \mathrm{C}$ or more was surpassed, the gas-atomized $\mathrm{Al}$ 6061 and conventionally cast Al 6061 DSC curves steadily decreased in a comparable manner until a temperature of $400^{\circ} \mathrm{C}$ was reached during testing.

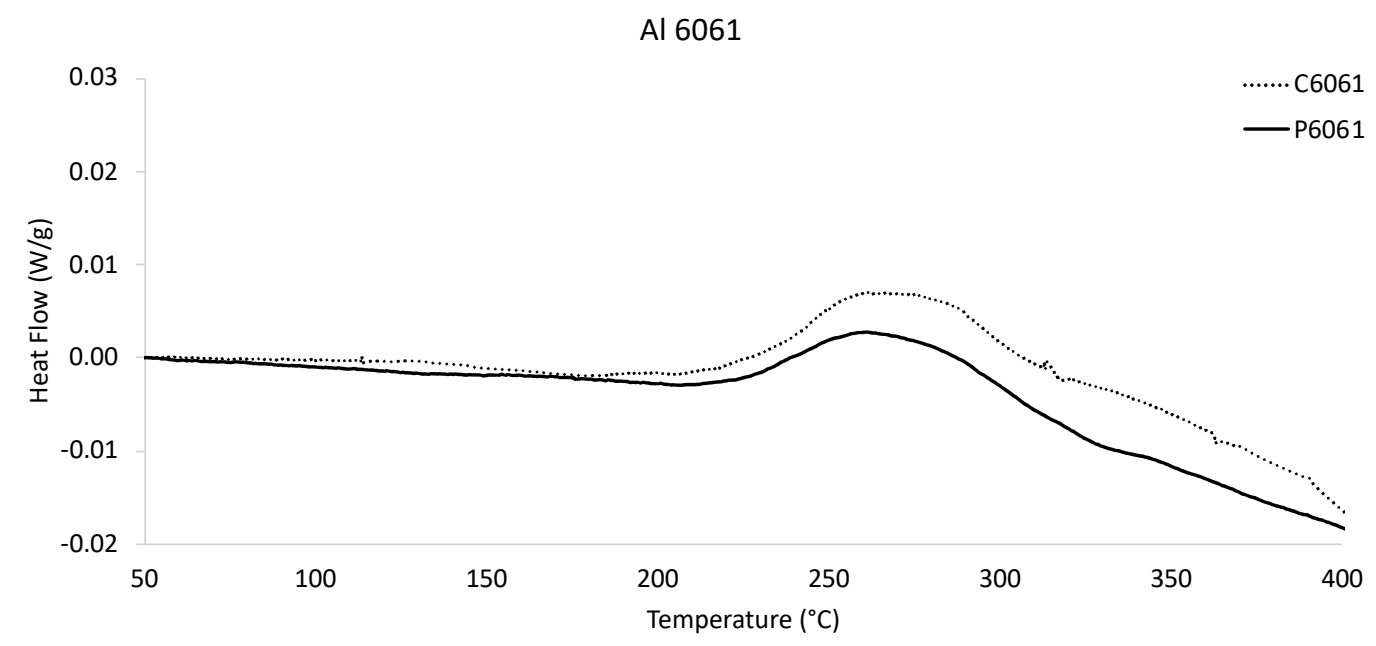

Figure 6. Differential scanning calorimetry-derived heat flow versus temperature curves for the as-cast as well as the as-atomized $\mathrm{Al} 6061$ materials.

In the case of the as-cast Al 2024 versus the gas-atomized Al 2024 DSC thermogram (shown in Figure 5), the kinetics associated with secondary phase formation and/or dissolution, as a function of temperature, was virtually absent from the as-cast Al 2024 DSC curve. Furthermore, the cast DSC-based behavior for $\mathrm{Al} 2024$ was clearly discernable from that of the gas-atomized data for $\mathrm{Al}$ 2024, which contained multiple, obvious exothermic and endothermic responses. Alternatively, the Al 6061 heat flow versus temperature curves affiliated with the conventionally cast specimen and rapidly solidified powder were uniquely similar to one another (shown in Figure 6). More to the point, the gas-atomized Al 6061 DSC curve contained confidently identifiable secondary phase formation peaks, whereas the gas-atomized Al 2024 DSC curve housed phase formation local maxima and phase 
dissolution minima. Given the appreciable differences between the Al 2024 thermogram and the $\mathrm{Al} 6061$ thermogram, the defining phase formation/dissolution curve characteristics of the cast $\mathrm{Al} 7075$ and rapidly solidified Al 7075 systems are shown in Figure 7.

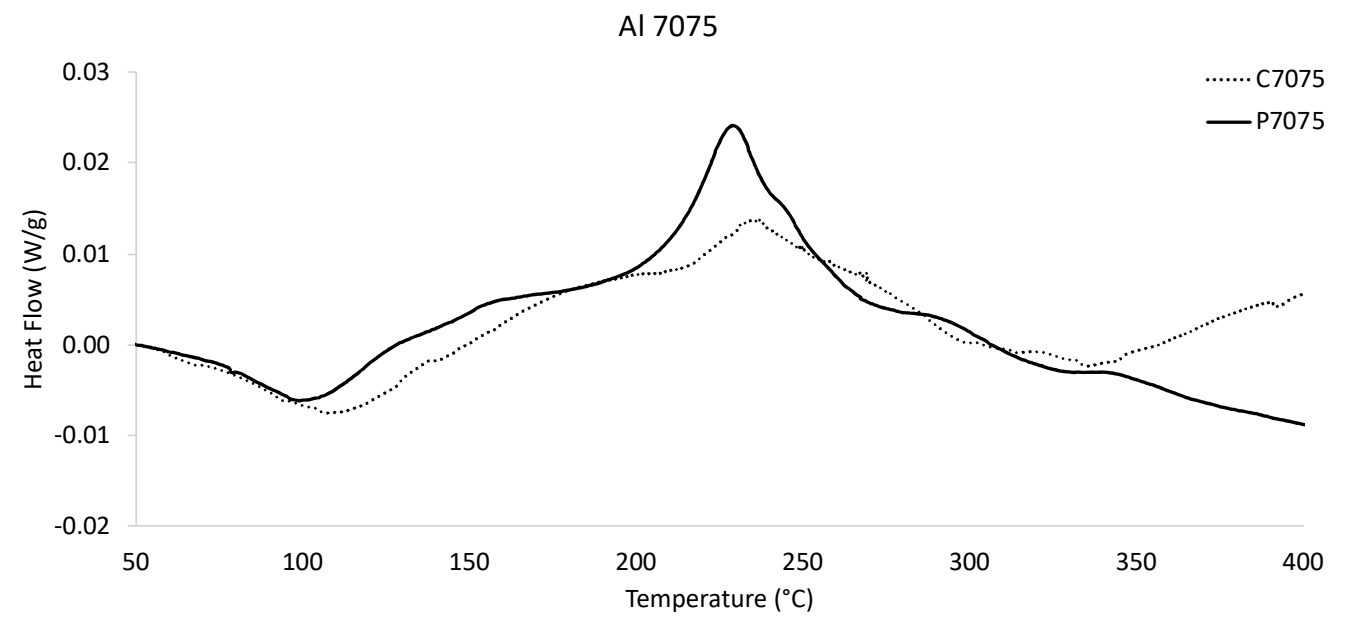

Figure 7. Differential scanning calorimetry-derived heat flow versus temperature curves for the as-cast as well as the as-atomized Al 7075 materials.

Although the similarity of the Al 7075 DSC curves was also self-evident via comparative analysis, the casting DSC data was shifted to the right. That is to say, similar secondary phase formation/dissolution peaks were present in the bulk specimen and the microparticles; however, the temperature about which such instances achieve regional maxima/minima was greater in the castings than that of the gas-atomized Al 7075. Specifically, secondary phase dissolution appears in both the cast and gas-atomized specimens at approximately 100 and $110{ }^{\circ} \mathrm{C}$, respectively. Secondary phase formation peaks are also found between 200 and $250^{\circ} \mathrm{C}$ for both material conditions. Intriguingly, the maximum heat flow value at the peak just identified for the gas-atomized $\mathrm{Al} 7075$ powder was greater than that of the magnitude of the peak in the counterpart's data.

Between 250 and $350{ }^{\circ} \mathrm{C}$, both of the Al 7075 DSC curves continuously decrease in a largely consistent manner. That said, fine-scale inspection of the way in which the Al 7075 heat flow values defined within 250 and $350{ }^{\circ} \mathrm{C}$ revealed a local quasi-sinusoidal oscillation of the heat flow values for each condition while also steadily decreasing on average as the temperature increases until reaching a temperature of $350{ }^{\circ} \mathrm{C}$. Lastly, a clear divergence between the as-cast $\mathrm{Al} 7075$ and gas-atomized $\mathrm{Al} 7075$ DSC responses was attained. Stated otherwise, the Al 7075 casting appeared to approach another occurrence of secondary phase formation. Yet, the gas-atomized Al 7075 DSC response was consistent with the onset of dissolution.

Figure 8 shows example optical micrographs for Al 7075 after etching. Specifically, the micrograph on the left-hand side of Figure 8 shows the as-cast condition, and the micrograph on the right-hand side of Figure 8 shows the as-atomized powder condition. These micrographs were used to calculate the grain size and qualitatively show the drastic size difference between the polycrystalline microstructure in powders versus their cast counterparts. As will be discussed hereafter, this contributes to the difference in hardness (Hall-Petch relationship) and a difference in secondary phases (diffusion distance to grain boundaries). 
(a)

(b)

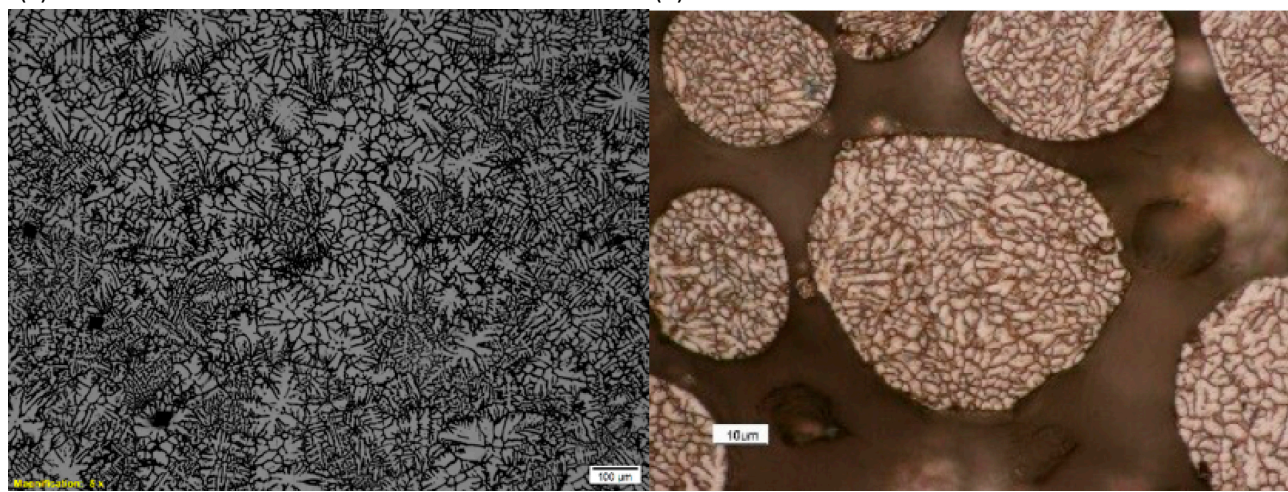

Figure 8. Chemically etched optical micrographs for the (a) as-cast and (b) as-atomized Al 7075 systems. Note that the scale bar associated with the as-cast chemically etched optical micrograph represents $100 \mu \mathrm{m}$, while the scale bar associated with the chemically etched gas-atomized Al 7075 micrograph was $10 \mu \mathrm{m}$, thus highlighting the difference in microstructural sizes due to differences in cooling rates.

Figure 9 shows electron micrographs comparing the microstructures of the as-cast, as-atomized, thermally treated cast, and thermally treated gas-atomized powder via SEM for Al 7075. The difference in granular structure seen in Figure 8 can be seen here again. Qualitatively, the powder and cast in the thermally treated condition (Figure 9b,d) are similar in that there are discrete phases, both light and dark contrasting. However, the as-atomized and as-cast structures are quite different. The as-cast structure has discrete phases, whereas the as-atomized powder structure has an interconnected network of phases at the boundaries. This is likely due to the solidification times; the cast condition cooled much slower than the powder (rapid solidification via gas atomization), allowing more secondary phases to form.
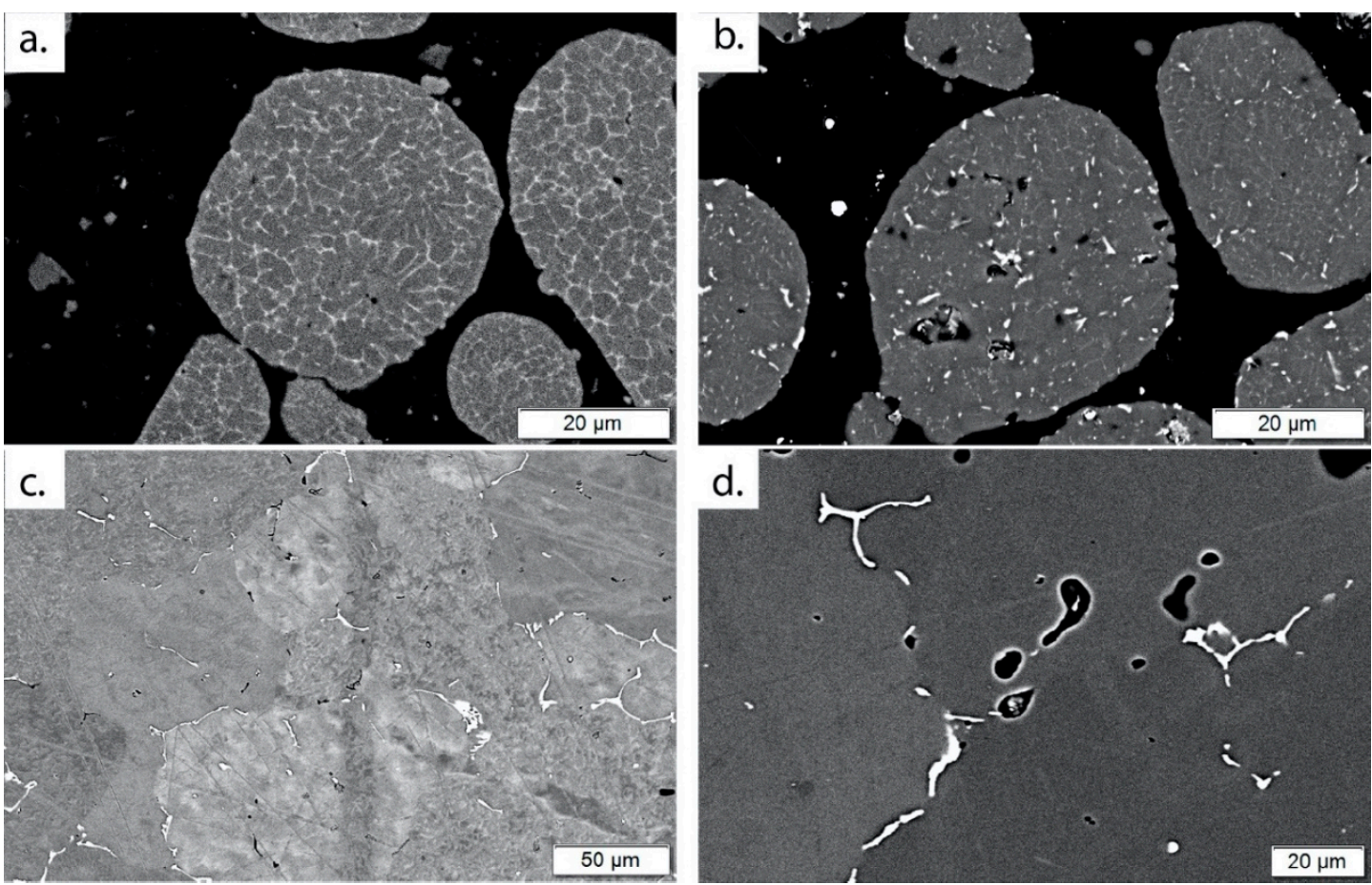

Figure 9. Electron micrographs comparing the microstructures of the as-cast (c), as-atomized (a), thermally treated cast (d), and thermally treated gas-atomized powder (b) via SEM for Al 7075. 
The secondary phase area percent of each alloy is presented in relation to each of the conditions studied herein. More specifically, the phase area percentages for the as-cast, as-atomized, thermally treated casts, and thermally treated gas-atomized powders are shown in Table 4. Table 4 is further refined in terms of the $\mathrm{Mg}$ or $\mathrm{Fe}$, or equivalent substitutional elements for a given phase, and the richness of each of the phases was analyzed. Figure 10 shows scanning transmission electron micrographs of the processed $\mathrm{Al} 6061$ powder, highlighting the secondary phases. Additionally, diffraction-based analysis was performed on the dark phase, revealing it to be $\mathrm{Mg}_{2} \mathrm{Si}$. This phase was also found in the cast $\mathrm{Al} 6061$, although the amounts present differ.

Table 4. The phase area percentages for the as-cast, as-atomized, thermally treated casts, and thermally treated gas-atomized powders.

\begin{tabular}{ccccc}
\hline \multirow{2}{*}{ Aluminum Alloy } & Processing Condition & $\begin{array}{c}\text { Mg-Rich Secondary } \\
\text { Phase Area }\end{array}$ & $\begin{array}{c}\text { Fe-Rich Secondary } \\
\text { Phase Area }\end{array}$ & $\begin{array}{c}\text { Total Secondary } \\
\text { Phase Area }\end{array}$ \\
\hline \multirow{3}{*}{2024} & as-cast & $0.29 \%$ & $1.15 \%$ & $1.44 \%$ \\
\cline { 2 - 5 } & as-atomized & - & $7.10 \%$ & $7.10 \%$ \\
\cline { 2 - 5 } & HT-cast & $0.61 \%$ & $0.98 \%$ & $1.59 \%$ \\
\hline \multirow{2}{*}{6061} & HT-atomized & - & $7.90 \%$ & $7.90 \%$ \\
\cline { 2 - 5 } & as-cast & $0.24 \%$ & $1.62 \%$ & $1.86 \%$ \\
\cline { 2 - 5 } & as-atomized & - & $16.00 \%$ & $16.00 \%$ \\
\cline { 2 - 5 } & HT-cast & $0.10 \%$ & $1.93 \%$ & $2.03 \%$ \\
\cline { 2 - 5 } 7075 & HT-atomized & $0.40 \%$ & $4.29 \%$ & $4.69 \%$ \\
\cline { 2 - 5 } & as-cast & $0.82 \%$ & $13.75 \%$ & $13.35 \%$ \\
\cline { 2 - 5 } & as-atomized & - & $0.85 \%$ & $2.47 \%$ \\
\cline { 2 - 5 } & HT-cast & $1.62 \%$ & $10.46 \%$ & $10.74 \%$ \\
\hline
\end{tabular}
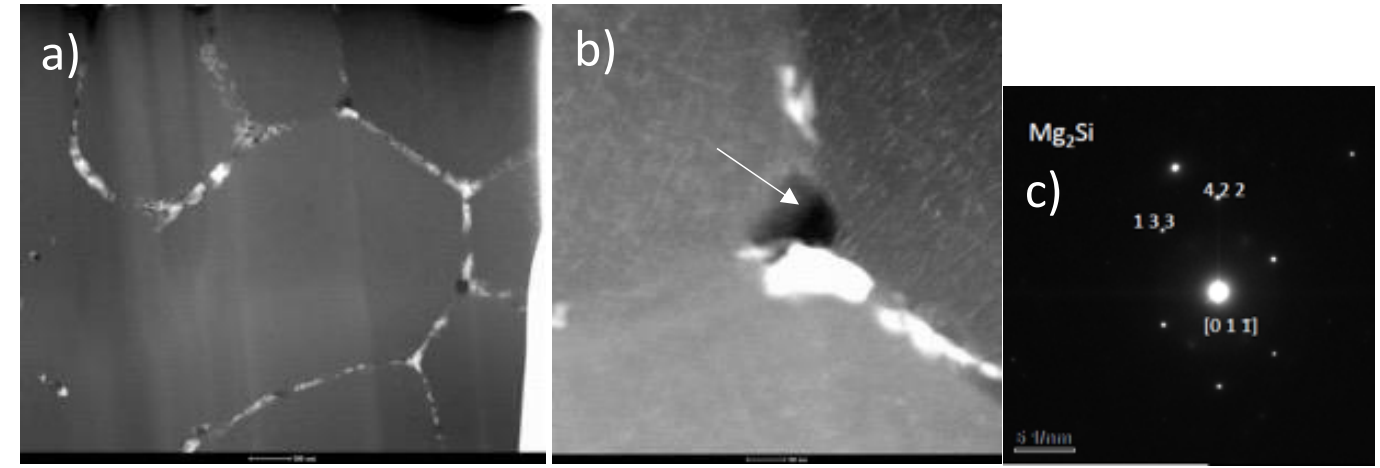

Figure 10. Scanning transmission electron micrographs and crystallographic data of the processed Al 6061 powder, highlighting the secondary phases (a). Additionally, diffraction-based analysis was performed on the dark phase $(\mathbf{b})$, revealing it to be $\mathrm{Mg}_{2} \mathrm{Si}(\mathbf{c})$.

The microstructural feature sizes for the three alloys are given in Table 5. Similar to Table 4, Table 5 presents the grain sizes ( $\lambda_{x}$, or secondary dendrite arm spacing (SDAS), and DAS sizes) for each of the conditions, which includes the as-cast, as-atomized, thermally treated casts, and thermally treated and powders. Lastly, the VHNs for each of the alloys in all four conditions are given in Table 6. 
Table 5. The grain sizes for each of the conditions, which includes the as-cast, as-atomized, thermally treated casts, and thermally treated powders.

\begin{tabular}{ccc}
\hline Aluminum Alloy & Processing Condition & SDAS/DAS Size $(\mu \mathrm{m})$ \\
\hline \multirow{3}{*}{ Al 2024 } & as-cast & 8.92 \\
\cline { 2 - 3 } & as-atomized & 1.26 \\
\cline { 2 - 3 } & HT-cast & 11.33 \\
\hline \multirow{2}{*}{ Al 6061 } & HT-atomized & 1.62 \\
\cline { 2 - 3 } & as-cast & 12.84 \\
\cline { 2 - 3 } & as-atomized & 1.41 \\
\hline & HT-cast & 13.61 \\
\cline { 2 - 3 } Al 7075 & HT-atomized & 1.53 \\
\cline { 2 - 3 } & as-cast & 9.22 \\
\cline { 2 - 3 } & as-atomized & 1.49 \\
\cline { 2 - 3 } & HT-cast & 10.53 \\
\hline
\end{tabular}

Table 6. The Vickers Hardness Numbers (VHNs) for each of the alloys in all four conditions are presented herein. In the case of nanoindentation-derived VHNs, the indentation size effect-inspired corrections were implemented to ensure accurate and direct comparison between bulk hardness values and powder hardness's.

\begin{tabular}{cccc}
\hline Aluminum Alloy & Processing Condition & $\begin{array}{c}\text { Vickers Hardness } \\
\text { Number (VHN) }\end{array}$ & $\begin{array}{c}\text { Indentation Size Effect } \\
\text { Corrected Hardness }\end{array}$ \\
\hline \multirow{2}{*}{2024} & as-cast & 50.00 & 50.00 \\
\cline { 2 - 4 } & as-atomized & 166.60 & 124.95 \\
\cline { 2 - 4 } & HT-cast & 53.00 & 53.00 \\
\cline { 2 - 4 } 6061 & HT-atomized & 184.50 & 138.38 \\
\cline { 2 - 4 } & as-cast & 59.00 & 59.00 \\
\cline { 2 - 4 } & as-atomized & 115.70 & 86.78 \\
\hline \multirow{2}{*}{7075} & HT-cast & 54.00 & 54.00 \\
\cline { 2 - 4 } & HT-atomized & 111.10 & 124.00 \\
\cline { 2 - 4 } & as-cast & 124.00 & 147.75 \\
\cline { 2 - 4 } & as-atomized & 197.00 & 134.00 \\
\cline { 2 - 4 } & HT-cast & 224.00 & 168.00 \\
\hline
\end{tabular}

\section{Discussion}

\subsection{On Comparing Indentation Hardnesses}

The indentation size effect (ISE) has been widely studied since Nix and Gao formally presented a strain gradient plasticity model to conceptualize the observed decrease in hardness as a function of indentation depth $[29,30]$. As such, an analytical framework was introduced that enabled hardness $(H)$ versus indentation depth $(h)$ data to be fit to Equation (8), such that

$$
\left(\frac{H}{H_{0}}\right)^{2}=1+\frac{h^{*}}{h}
$$


where $H_{0}$ is the hardness in the infinite depth limit, in other words, the true hardness of the material, and $h^{*}$ is a characteristic length that depends on the shape of the indenter, the shear modulus, and $H_{0}$ [30]. Accordingly, the direct application of curve-fitting procedures enables one to directly obtain $H_{o}$ and $h^{*}$ from experimentally measured nanoindentation data. The underlying physical and mechanical relations associated with $H_{0}$ and $h^{*}$ are mathematically formulated in Equation (9), such that

$$
H_{0}=3 \sqrt{3} \alpha \mu b \sqrt{\rho_{S S D}}
$$

and Equation (10), such that

$$
h^{*}=\frac{81}{2} \alpha^{2} b \tan ^{2}(\Theta)\left(\frac{\mu}{H_{0}}\right)^{2}
$$

In Equations (9) and (10), $\alpha$ is a constant, $0.5, b$ is the Burgers vector, $\mu$ is the shear modulus, $\Theta$ is the geometric angle separating the surface of the indenter tip and the material surface orthogonal to the direction of indentation, and $\rho_{S S D}$ is the density of statistically stored dislocations introduced by the process of indenting to a given depth [30]. Although the aforementioned plasticity parameters $\left(H_{0}\right.$ and $h^{*}$ ) are identifiable by way of direct analysis of the nanoindentation data according to Equation (8), $H_{o}$ can also be obtained by surpassing or achieving an indentation depth of $2000 \mathrm{~nm}$ [31]. Since the reported hardness's of the gas-atomized powders were reported at a depth of $250 \mathrm{~nm}$, it is reasonable to assume that the ISE caused the recorded hardness to be higher than that of $H_{0}$ and therefore questionably comparable with the VHNs obtained for the cast material systems without prior transformation to an equivalent $H_{0}$ value.

Considering the fact that $H_{o} \cong H_{2000}$, additional testing of $\mathrm{Al} 7075$ gas-atomized powder using dynamic, that is, the continuous stiffness measurement (CSM) method, and an MTS Nanoindenter XP enabled the $H_{250}$ nanoindentation hardness to be compared with that of $H_{500}$ and $H_{2000}$ to identify a proportionality that allowed the $H_{250}$ data to be converted to an approximately lower limit value for $H_{o}$ given the influence of the mounting material upon particle indentation at such depths, too [27]. Proper conversion of the $H_{250}$ data to an equivalent $H_{0}$ value enables direct comparison with the HVN obtained for the cast samples. As illustrated through the consideration of Figure 11, it was shown that the $H_{250}$ is approximately equivalent to $H_{500}$, which is approximately equal to $(0.75) H_{2000}$.

Therefore, Equation (11) may be expressed as follows:

$$
\left(\frac{3}{4}\right) H_{250} \cong H_{2000} \cong H_{0}
$$

The described approach to converting the $H_{250}$ to a virtually equivalent $H_{0}$ value, which can be directly compared with the VHNs measured for the bulk materials, is worth critical assessment. Such a critical assessment need not follow from the approximate equivalence relation between $H_{250}, H_{500}$, $H_{2000}, H_{0}$, and VHNs; rather, an important question arises surrounding the choice to measure powder particle properties at a depth of $250 \mathrm{~nm}$ instead of $2000 \mathrm{~nm}$ or through the use of a nanoindenter instead of a conventional Vickers or micro-indentation tester. The choice of a nanoindentation depth of $250 \mathrm{~nm}$, as well as the use of a nanoindenter over a microhardness tester for powder, follows from the fact that powder particle mounting material matrix has been shown to affect the recorded nanoindentation data if care is not taken when performing such characterization [27].

The influence of mounting materials upon the nanoindentation of metallic powder particles embedded in a more compliant medium was initially brought to light by Shives et al. at the microindentation scale [32]. The work by Shives et al. has unfortunately gone relatively unnoticed as evidenced by the limited number of times their published findings have been cited (six citations at the time this article was written, according to Google Scholar). In any case, since the maturation of nanoindentation over the course of the previous two to three decades, researchers have even observed a mounting material effect at the nanoindentation scale [33]. 

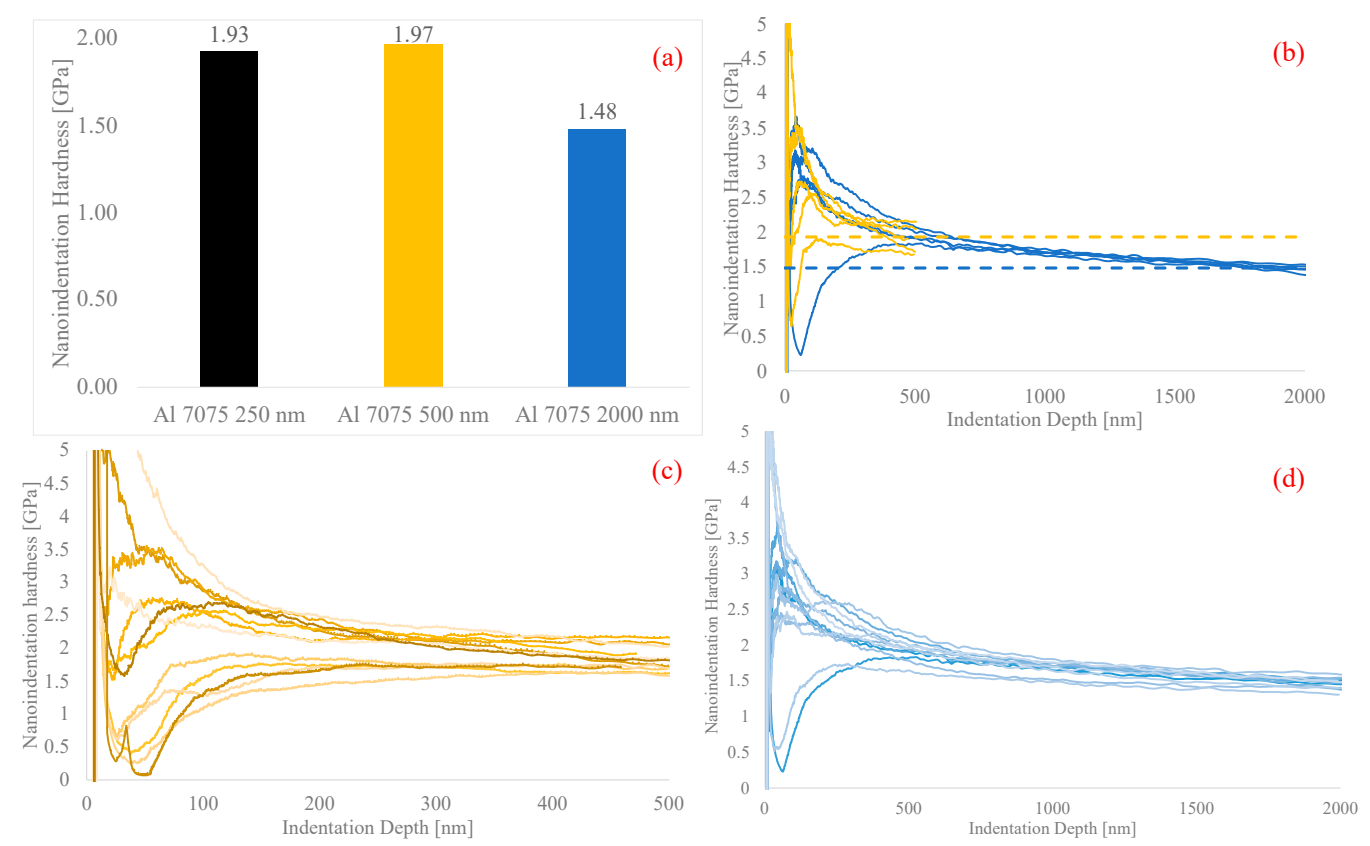

Figure 11. Illustration of the proportionality between the various hardness's versus depth. (a) demonstrates the average hardness of $\mathrm{Al} 7075$ gas-atomized powder particles at dynamic nanoindentation depths of $250 \mathrm{~nm}, 500 \mathrm{~nm}$, and $2000 \mathrm{~nm}$. (b) plots the data presented in (c,d) together in order to capture the average hardness values at $500 \mathrm{~nm}$ and $2000 \mathrm{~nm}$, respectively. (c,d) plot the hardness vs. depth curves for the dynamic nanoindentation performed upon Al 7075 particles until two different maximum depths were achieved. Of course, the particle-dominated depth limit detailed in [27] was notably surpassed for (d) herein; thus, making the values of hardness recorded at $2000 \mathrm{~nm}$ as being less than the true particulate hardness. Nevertheless, it enabled the formulation of a baseline proportionality for addressing the ISE and therefore enabling direct comparisons to be made between the cast and atomized materials.

From the late 1990s and early 2000s, nanoindentation researchers have been raising concerns regarding the need for the continued development of models for evaluating plastic and elastic properties of hard particles embedded in relatively softer mounting material [33-36]. Researchers have applied a "thin film" correction to the protocol for indentation testing of powder in a mounting resin. The underlying intuition behind this adaptation of indentation testing is certainly commendable [8,37]. Unfortunately, the geometrical variation behind a planer thin film on a compliant substrate is not similar enough to an embedded hemispherical particle surrounded by a compliant mounting material, which is otherwise analogously similar to a complaint substrate. Careful consideration of the previously reported findings within the literature has found that the thin film protocol cannot be extended to particle/matrix systems [36,38].

Notably, even when experimentally considering a number of models developed for correctly extracting particle hardness given a softer mounting material effect, the data collected during the course of our research speaks to the need for continued refinement of the currently available models. For example, Cao et al. proposed that the hardness of a stiffer particle embedded in a soft mounting material can be collected with less than $10 \%$ error if the following relation, given in Equation (12), was adhered to [36], such that

$$
h_{m}=0.135(R)
$$

where $h_{m}$ is equivalent to the maximum indentation depth of a particle before the softer mounting material affects the measured hardness, and $R$ is the radius of a given particle.

By way of solving for $h_{m}$ for a particle with a radius of approximately $19 \mu \mathrm{m}$, derived from the average $D_{50}$ reported in Table 2 for each of the three Al powders, one calculates $h_{m}$ of $2565 \mu \mathrm{m}$. 
Fortunately, previous work by Chen et al. reported indentation properties for gas-atomized $\mathrm{Al} 6061$ at depths near $2565 \mu \mathrm{m}$ in a soft epoxy and measured hardness values between 0.15 and 0.51 GPa [39], which is absolutely far too low for $\mathrm{Al} 6061$ gas-atomized powder and therefore speaks to the limitation of Cao et al.'s model $[8,37,40]$. Regardless of the model proposed by [36] that aims to quantify an indentation depth limit, one could alternatively consider the plastic zone radius for a given indentation load and can be defined according to continuum mechanics [41], such that Equation (13) is given as

$$
c=\sqrt{\frac{3}{2 \pi} \frac{P}{\sigma_{y s}}}
$$

where $c$ is the plastic zone radius, $P$ is the applied load, and $\sigma_{y s}$ is the yield strength of the powder particle. Alternatively, the plastic zone radius has been defined by Chen et al. in [42], given in Equation (14) as follows,

$$
c=\sqrt{\frac{0.3 P}{\sigma_{y s}}}
$$

The magnitude of the plastic zone radius was calculated by way of utilizing the SDAS, and therefore the effective grain size data presented in Figure 3 and listed in Table 5 to predict the yield strength. Keeping with $\mathrm{Al} \mathrm{6061,} \mathrm{the} \mathrm{yield} \mathrm{strength} \mathrm{for} \mathrm{the} \mathrm{powder} \mathrm{was} \mathrm{determined} \mathrm{via} \mathrm{the} \mathrm{Hall-Petch} \mathrm{relation,}$ which is given in Equation (15) as follows,

$$
\sigma_{y}=\sigma_{o}+\frac{k}{\sqrt{D}}
$$

where $\sigma_{y}$ is the yield strength of the powder particle, $D$ is the average grain size, $\sigma_{o}$ is rationalized as a frictional stress resisting the motion of gliding dislocations, and $k$ is a measure of the resistance of the grain boundary against slip transfer [43]. For alloyed aluminum gas-atomized powder, $\sigma_{o}=200 \mathrm{MPa}$ and $k=0.14 \mathrm{MPa} \mathrm{m}^{1 / 2}$.

By that rational, and by way of considering the application of a microindenter with a lower load limit of $0.01 \mathrm{kgf}$, it follows that for an aluminum alloy, the plastic zone radius is between 11 and $14 \mu \mathrm{m}$, assuming the two models above. While we could argue that for a particle of $38 \mu \mathrm{m}$ diameter, the predicted plastic zone radius from continuum mechanics alone is less than the particle radius and therefore feasible, work by others began to incorporate the occurrence of dislocation accumulation into the prediction of a more refined plastic zone radius. Therefore, when dislocations are considered as well for the $0.01 \mathrm{kgf}$ applied to said powder particle, the plastic zone radius is actually between 55 and $75 \mu \mathrm{m}$, which exceeds the powder particle radius by two to three times [44], thus including the effect of the mounting material on the measured hardness.

For the sake of completion, if we assume an applied nanoindentation load of $0.005 \mathrm{~N}$ for a similar Al 6061 powder particle with a yield strength of $273 \mathrm{~N} \cdot \mathrm{mm}^{-2}$, then the plastic zone radius would be between 2.33 and $2.94 \mu \mathrm{m}$ from continuum mechanics alone. From a cautionary standpoint, if the accumulation of dislocations is considered once more, then the combined plastic zone radius range is between 11.66 and $14.71 \mu \mathrm{m}$, where both of which are less than the radius of the $\mathrm{D}_{50}$ powder particle, therefore ensuring that the nanoindentation depth is effectively free of a mounting material influence.

\subsection{Al 7075 Powder as a Case Study}

Although this paper addresses the lack of scientific literature explicitly differentiating the nature of GA (rapidly solidified) alloyed Al powders with their cast (slowly solidified) counterparts, previous work has investigated the microstructure-processing-properties-performance paradigm for cold spray by focusing upon powder pre-processing effects. Focusing upon Al 7xxx, Sabard et al. studied the consolidation of solution heat treated, naturally aged, and artificially aged Al 7075 in relation to cold spray [45]. In order to thermally pre-process their 7075 powder, Sabard et al. elected to secure 
powder within a tube of quartz and perform heat treatments using a commercially available box furnace. Sintering of powders was not noted by this work, nor was cooling rate during quenching measured [46]. Beyond the limitations identified by Liu et al. surrounding Sabard et al.'s work, differences also exist between the methods reported herein and those deployed during Sabard et al.'s work. Specifically, a DSC was utilized to perform thermal processing in order to ensure that the processing conditions were near ideal and the cooling rates were maximized to ensure that the thermally processed microstructure was retained upon cooling. Consideration of the kinetics associated with the formation and modification of $\mathrm{Al}$ alloyed powders has demonstrated much more rapid rates of phase transformation versus that of bulk material $[14,24,25,37,47]$.

Similarly, noteworthy differences between Sabard et al.'s research methodology and our own follows from the fact that $480{ }^{\circ} \mathrm{C}$ was used during the course of this work for the purpose of solutionization instead of the conventional standard heat-treating temperature prescribed for bulk Al 7075 alloys. This temperature was selected according to the equilibrium phase diagram obtained using the measured chemical make-up of the Al 7075 powder reported herein by way of the computational materials software Thermo-Calc. The respective phase diagram has previously been reported upon in [26]. One may suspect that a $5{ }^{\circ} \mathrm{C}$ difference in the processing temperature would have limited effects.

However, the slightly greater difference of $15^{\circ} \mathrm{C}$ relative to $465{ }^{\circ} \mathrm{C}$ was shown to form the S-phase $\left(\mathrm{Al}_{2} \mathrm{CuMg}\right)$ alongside the T-phase $\left(\mathrm{Al}_{2} \mathrm{Mg}_{3} \mathrm{Zn}_{3}\right)$, whereas the $480{ }^{\circ} \mathrm{C}$ treatment did not form the S-phase and achieved greater dissolution of the T-phase at $1 \mathrm{~h}$. Interestingly, Sabard et al. did not discuss the implications of phases such as $\mathrm{Al}_{2} \mathrm{CuMg}$ or $\mathrm{Al}_{2} \mathrm{Mg}_{3} \mathrm{Zn}_{3}$ and only considered Guinier-Preston (GP) zones and $h / h^{\prime}\left(\mathrm{Mg}(\mathrm{Zn}, \mathrm{Al}, \mathrm{Cu})_{2}\right)$ in [45]. From the associated phase diagram in [26], $480{ }^{\circ} \mathrm{C}$ is also more optimal in terms of avoiding any unexpected or non-predicted local equilibria phenomena within the powder, since the highly non-equilibrium nature of rapid solidification is not completely captured through the thermodynamic approach taken in computationally formulating a phase diagram with Thermo-Calc, as illustrated through the unexpected formation of $\mathrm{Al}_{2} \mathrm{CuMg}$ at $465{ }^{\circ} \mathrm{C}$, for example.

Three additional differences between the findings reported by Sabard et al. and the research presented herein concerns the DSC analysis approach to characterizing the hardness of the powders and the supplier/chemistry/manufacturing of the $\mathrm{Al} 7075$ powders used. With respect to the supplier of the powder, our research was performed upon Al 7075 powder purchased from Valimet, Inc (Stockton, CA, USA). On the other hand, Sabard et al. acquired their feedstock material from TLS Technik and found the $\mathrm{D}_{10}, \mathrm{D}_{50}$, and $\mathrm{D}_{90}$ to be $31.5,48.5$, and $73.1 \mu \mathrm{m}$, respectively. Compared with the PSD characteristics associated with the $\mathrm{Al} 7075$ powder presented during the course of this research, Sabard et al.'s $\mathrm{D}_{10}$ was $20.69 \%$ larger, while their $\mathrm{D}_{50}$ and $\mathrm{D}_{90}$ were $30.73 \%$ and $38.19 \%$ greater, respectively.

Of more immediate relevance is the chemical discrepancy between the TLS Technik spherical gas-atomized Al 7075 powder and the $\mathrm{Al} 7075$ powder from Valimet, which is based on the difference in the alloying element content between the two batches of powder. Although the powder used by Sabard et al. is also within the ASM specification standard, certain alloying elements were significantly varied in contrast with one another. While $\mathrm{Cr}, \mathrm{Zn}, \mathrm{Cu}$, and $\mathrm{Mg}$ were found to be virtually equivalent in weight percent, the TLS Technik powder had $33.33 \%$ more Si and $17.65 \%$ more Fe.

Alternatively, there was $80.77 \%$ less Mn in the TLS powder as well as $65.52 \%$ less Ti. Slight variations in alloying composition, even within tolerable ranges, have been shown to vary the tendency to form specific secondary phases, precipitates, and dispersoids [14]. Such variation in alloying elemental content can also serve to shift the temperature required for phase dissolution, thus speaking to the need for Sabard et al. to refine future work through the use of chemistry-specific thermodynamic phase diagrams using platforms such as Thermo-Calc, FactSage (Thermfact/CRCT, Montreal, Canada and GTT-Technologies, Aachen, Germany), or Pandat (CompuTherm LLC, Middleton, WI, USA), among others, when designing thermal processing parameters for powder.

Even though prior and forthcoming work has demonstrated the fact that alloying elements that are not contained within a given phase can influence the tendency of such a phase to nucleate within a 
material [14], the specific elemental constituents within a given phase are still the main driving force behind the likelihood of a particular phase's formation. Accordingly, since $\mathrm{Zn}, \mathrm{Mg}$, and $\mathrm{Cu}$ were effectively equivalent between the two batches of powder, it was surprising that $h / h^{\prime}$ was assumed. As such, Sabard et al. would benefit from continued refinement of their future work by way of applying TEM-based energy dispersive X-ray spectroscopy analysis of the nano-scale precipitates formed within as-atomized and thermally processed $\mathrm{Al} 7075$ powders instead of assuming a conventional strengthening sequence of GP zones to $h / h^{\prime}$.

Due to the fact that the strengthening sequence depends upon the ratio of $\mathrm{Mg} / \mathrm{Zn}$ and the fact that both $\mathrm{Mg}$ and $\mathrm{Zn}$ were virtually equivalent between the Valimet and TLS powders, it stands to reason that the actual strengthening phase sought after by Sabard et al. is $\mathrm{Al}_{2} \mathrm{Mg}_{3} \mathrm{Zn}_{3}$. More to the point, the focus upon $h / h^{\prime}$ by Sabard et al. is also inconsistent when compared with their earlier work, which attempted to analyze elemental mapping within Al 7075 powder that was sourced from Valimet via SEM-EDS analysis. Given the lack of confidence in phase specification that they articulated in an earlier manuscript, the more recent focus upon $\mathrm{h} / \mathrm{h}^{\prime}$ three years after their original proclamation is surprising.

Beyond the work of Sabard et al., Rokni et al. previously characterized the microstructure of Al 7075 gas-atomized powder [6]. Rokni et al. also purchased their powder from a different supplier than the one selected during the course of this research, which was also different from the manufacturer selected by Sabard et al. [45]. Rokni et al. reportedly sourced their Al 7075 powder from CenterLine (Windsor) Limited; however, a current survey of their presently offered powder products seems to no longer consist of 7xxx series powder as a consumer option. Therefore, a limited analysis of processing parameters can be made. Regardless of the varied supplier in this case, it is important to note that Rokni et al. elected to favor the formation of $\eta$ in the form of $\mathrm{MgZn}_{2}$ precipitates, even though they conceded that the possible primary precipitates in this alloy are $\eta\left(\mathrm{MgZn}_{2}\right), \eta\left(\mathrm{MgZn} \mathrm{n}_{2}\right)$, $\mathrm{Mg}(\mathrm{Zn}, \mathrm{Cu}, \mathrm{Al})_{2}$, and $\mathrm{T}$ phase $\left((\mathrm{Al}, \mathrm{Zn})_{49} \mathrm{Mg}_{32}\right)$ [6]. Although preliminary EDS analysis was interpreted as being potentially suggestive of $\eta$, Rokni et al. admits that a detailed study of the precipitate composition and structure was lacking in their study.

The observation of the T-phase in the as-atomized 7075 powder reported upon herein [26] is also consistent with powder X-ray diffraction (PXRD) performed by Molnárová et al. and substantiated by [48], wherein Molnárová identified $<1$ wt. $\%$ content of $\mathrm{Mg}_{32}(\mathrm{Zn}, \mathrm{Al}, \mathrm{Cu})_{49}$ as the predominant precipitate [49]. In [49], the authors claim that microhardness measurements enable strength comparisons between powders. They measured Vickers microhardness of atomized powder particles as $95 \pm 18 \mathrm{HV}$; the large standard deviation is attributed to variation in powder particle microstructures due to solidification rates. As discussed in the aforementioned sections, the use of a microhardness tester for measuring powder and recording such low values for $\mathrm{Al} 7075$ powder speaks to the limitation of the reasoning underlying the quoted passage provided.

\subsection{Additional Analysis of the Reported Results}

Figure 1 shows the temperature of the three casts as a function of time, which speaks to the cooling rates experienced by the cast materials in contrast to the rapidly solidified powders. Figure 2 contrasts the cast cooling rates with time. The cooling rates expected in both cases are consistent with those presented in earlier works [50,51]. In fact, the peak $\mathrm{Al} 6061$ cooling rate measured and presented in Figure 2 was found to be consistent with the peak cooling rate recorded by $\mathrm{Xu}$ et al. in a study concerned with the effect of cooling rates upon twin-rolled cast $\mathrm{Al} 6061$ when Xu et al.'s casting was allowed to cool and solidify in air [52].

Considering the $\mathrm{D}_{50}$ reported for gas-atomized $\mathrm{Al}$ 6061, for example, which was presented in Table 2, we may capture the order of magnitude associated with a gas-atomized Al 6061 powder particle with a diameter of approximately $40 \mu \mathrm{m}$. With the peak cooling rate associated with the conventionally cast counterpart in mind, by way of comparison, one readily appreciates the fact that the cooling rate for such a powder particle was multiple orders of magnitude greater than that associated with 
the casting $\left(10^{5}{ }^{\circ} \mathrm{C} \cdot \mathrm{s}^{-1}\right.$ versus $\left.10^{0}{ }^{\circ} \mathrm{C} \cdot \mathrm{s}^{-1}\right)$. Considering the fact that slight variations in the average cooling rates affiliated with cast $\mathrm{Al} 6061$ have previously been found to have significant effects on the mechanical properties and resultant microstructures of bulk counterparts, one can readily appreciate the consequences of the vastly different cooling rates for the atomized and cast systems studied herein, too. The same holds true when the $\mathrm{D}_{50}$ droplet cooling rates are compared with the cast cooling rates for $\mathrm{Al} 2024$ and $\mathrm{Al} 7075$ as well.

The relationship between grain size and particle diameter for $\mathrm{Al}$ 2024, $\mathrm{Al}$ 6061, and $\mathrm{Al} 7075$ ought to be noted herein, too. Experimental validation of the cooling rate calculations and computed effective grain sizes as a function of particle size also revealed the fact that an increase in particle diameter from 20 to $60 \mu \mathrm{m}$ increases the grain size by nearly three to four times for each aluminum alloy considered. Through the lens of the Hall-Petch relation between grain size and strength, one may also consider the implications for cold spray, as will be discussed in even greater detail hereafter. In the meantime, such variations between the particle strength as a function of particle diameter will vary the critical particle impact velocities required for particle-substrate bonding, wherein particles with a greater diameter would require lower critical impact velocities than that of smaller particles. Such an immediate observation is consistent with research by Dowding et al., which found that the critical velocity was approximately $33 \%$ greater for an aluminum particle of approximately $10 \mu \mathrm{m}$ in diameter compared with a particle of approximately $40 \mu \mathrm{m}$ in diameter [53].

In light of the compositional wt.\%'s measured by OES for the Al 2024 casting, limited comparative analysis can truly be expressed herein. In fact, the OES-based Cu wt.\% was not only out of ASM International specifications for $\mathrm{Al} 2024$, it was also much lower than the general copper content range prescribed to Al 2xxx series, which typically resides within a lower bound of $2 \mathrm{wt} . \%$ and an upper bound of $10 \mathrm{wt} . \%$ copper. More troubling is the fact that the measured OES-based Al 2024 cast Cu wt.\% was only $0.012 \mathrm{wt} . \%$, thus potentially acting as a trace element in a cast material that was supposed to be primarily alloyed with copper as the main alloying element. That being said, $\mathrm{Cu}$ was not the only alloying element in the cast $\mathrm{Al} 2024$ specimen found to be below or above the prescribed tolerances. Specifically, the $\mathrm{Cr}$ content was measured as $0.197 \mathrm{wt} . \%$, which is nearly double that of the allowable upper limit according to ASM International. On the other hand, the Mn content was only $0.06 \mathrm{wt} . \%$, and the $\mathrm{Mg}$ content exceeded the standardized upper bound at a value of $2.25 \mathrm{wt} . \%$.

Then, an attempt was made to rationalize and deduce what was potentially responsible for the measured out-of-range alloying elements. Understanding the source of the varied chemical composition within bulk $\mathrm{Al} 2024$ not only follows from the need to consider the limitations surrounding a direct comparison of the gas-atomized $\mathrm{Al} 2024$ properties with the powders' cast counterpart. Rather, the need for a reasonable explanation also stems from the desire to assess whether or not the $\mathrm{Al} 6061$ and $\mathrm{Al} 7075$ cast and gas-atomized conditions can be confidently compared with one another, too, given the fact that the cast $\mathrm{Al} 6061$ and $\mathrm{Al} 7075$ compositions were also obtained using the same OES system. Potential sources of error or influence with respect to the present issue at hand are formulated as follows: (1) OES device contamination, (2) elemental loss from inclusion formation during casting, (3) deterioration of the notably dated OES system available, (4) elemental loss from volatilization or evaporation during liquid processing, (5) errors in performing the casting process, and/or (6) out-of-specification wrought aluminum alloy casting feedstock. Given the number of potential sources that must be considered, continued discussion is provided next.

If OES-device contamination was responsible for the recorded $\mathrm{Cu}, \mathrm{Cr}, \mathrm{Mg}$, and $\mathrm{Mn}$ contents, one would expect to find errors throughout the $\mathrm{Al} 6061$ and $\mathrm{Al} 7075$ castings, too. To test the feasibility of the notion that (1) was responsible, one would expect the Mg content within the $\mathrm{Al} 6061$ and $\mathrm{Al} 7075$ castings to be overestimated, too. However, the fact that the wt.\% of Mg within the cast $\mathrm{Al} 6061$ sample was slightly lower than the specified lower limit of $0.8 \mathrm{wt} . \%$, at $0.66 \mathrm{wt} . \%$, detracts from the feasibility of explanation (1). The fact that the wt.\% of Mg within the cast $\mathrm{Al} 7075$ sample was within the defined range at $2.21 \mathrm{wt} . \%$ also detracts from (1) listed above as well. It is also worth noting that $\mathrm{Cr}, \mathrm{Cu}$, and $\mathrm{Mn}$ were all within specification for cast $\mathrm{Al} 6061$ and Al 7075, too, which once again nullifies (1). 
As for (2), one may test the veracity of the prospective explanation by way of focusing on the amount of $\mathrm{Cu}$ present in $\mathrm{Al} 6061$ and $\mathrm{Al} 7075$ casts, since one would expect the content to be substantially lower than the lower bound prescribed by ASM International. This is due to the fact that if copper was lost during casting by way of forming inclusions and slag at the molten or liquid Al 2024 surface, then one would reasonably expect alternative aluminum alloy systems to also lose a proportional amount of the element, too. From Figure 4, this was clearly not the case, since the $\mathrm{Cu} w \mathrm{wt} \%$ in the cast $\mathrm{Al} 7075$ material was within range, at a value of $1.36 \mathrm{wt} . \%$, and two orders of magnitude greater than the trace amount measured in the $\mathrm{Al} 2024$ casting via OES. Just as the $\mathrm{Al} 7075$ did not appear to support (2), the resultant $\mathrm{Cu}$ content within the cast $\mathrm{Al} 6061$ was also within an accepted range at $0.164 \mathrm{wt} . \%$. Therefore, claims (3) through (6) must endure continued consideration, analysis, and discussion herein.

Unlike claims (1) and (2), which required greater detail and explanation be presented to remove them from further consideration, (3) can more readily be nullified. If (3) was responsible for the out-of-specification alloying element contents measured via OES, then the Al 6061 and Al 7075 would have been deleteriously influenced in a comparable manner. Yet, as clearly shown in Figure 4, all of the elements out of range in the $\mathrm{Al} 2024$ specimen were found to be in accordance with specified tolerances for the Al 7075 cast counterpart. Similarly, the $\mathrm{Cu}, \mathrm{Cr}$, and Mn wt.\%'s within the cast Al 6061 were also well within specification, with only Mg being slightly lower than standard limits. Hence, the claim that instrument deterioration was responsible for the resultant Al 2024 casting composition does not hold either. Claim (4) can also be dismissed following a relatively straightforward comparison of the out-of-specification alloying elements in the $\mathrm{Al} 2024$ casting with the way in which they were found to be out of range (i.e., greater than the upper limits or less than the lower limits, respectively) and their particular boiling points.

Therefore, the most likely culprits are claims (5) and (6). In light of the fact that the casting process was successful for $\mathrm{Al} 6061$ and $\mathrm{Al} 7075$ castings, it stands to reason that errors in performing the casting process are less likely to be the primary source of $\mathrm{Al} 2024$ casting nullification than that of out-of-specification wrought aluminum alloy casting feedstock, as expressed in claim (6). Given the careful inspection of the prospective sources of error, one can conclude that $\mathrm{Al} 6061$ and $\mathrm{Al}$ 7075 comparisons between the bulk and atomized conditions hold, since (6) was responsible for the out-of-specification alloying element contents measured via OES and was therefore isolated to Al 2024.

Returning to Al 2024, Figure 5 presented the DSC curves for the nominally cast Al 2024 counterpart as well as the gas-atomized $\mathrm{Al} 2024$ powder. While limited knowledge can be ascertained by way of directly comparing the two $\mathrm{Al} 2024$ conditions with one another, given the compositional discrepancies just discussed in great detail, insights can still be derived from consideration of the DSC data for gas-atomized $\mathrm{Al}$ 2024. Compared with earlier works of scholarship that incorporated DSC-based analysis of Al 2024 materials into their research, the exothermic and endothermic gas-atomized $\mathrm{Al}$ 2024's peaks present in Figure 5 can be classified in accordance with the formation or dissolution of specific secondary phases. The initial local maxima about a temperature of $100{ }^{\circ} \mathrm{C}$ or so for the gas-atomized Al 2024 likely follows from the formation of GP zones.

The first local minima recorded during DSC analysis of rapidly solidified Al 2024 powder was found to be consistent with the dissolution of the GP zones. The second bimodal set of local maxima presented within the thermogram between $250{ }^{\circ} \mathrm{C}$ and more than $300{ }^{\circ} \mathrm{C}$ were consistent with the formation of coherent $\theta^{\prime \prime}$ phases followed by semi-coherent $\theta^{\prime}$ and $\mathrm{S}^{\prime}$ phase formation as well as $\theta$-phase and S-phase formation, too. At the same time, the unique solidification conditions associated with gas-atomized $\mathrm{Al} 2024$ processing has been shown to contain S-phase precipitates and $\mathrm{Al}_{2} \mathrm{Cu}$ precipitates in the as-atomized condition [25]. Such findings by Walde et al. are consistent with the partial attribution of S-phase secondary phase formation in Figure 5, too.

\subsection{Relation to and Implications for Cold Spray}

Within the cold spray community, powder-specific material properties have been sought after for the purpose of performing single-particle and multi-particle impact simulations and computational 
analysis via finite element analysis (FEA). Whether the Preston-Tonks-Wallace (PTW) approach is taken, which is partly presented in Equation (17), or the Johnson-Cook (JC) formulation [54], given in Equation (16), is entertained, material-dependent input parameters are required. The JC and PTW relations are expressed as follows,

$$
\sigma_{J C}=\left(A+B p^{N}\right)\left(1+C \log \frac{\dot{p}}{\dot{p}_{o}}\right)\left(1-\left(\frac{T-T_{0}}{T_{\text {melt }}-T_{o}}\right)^{M}\right)
$$

and

$$
\sigma_{P T W}=2\left\{\tau_{s}+\alpha \ln \left[1-\phi \exp \left(-\beta-\frac{\theta \epsilon_{p}}{\alpha \phi}\right)\right]\right\} \mu(p, T) .
$$

Traditionally, these values have been borrowed from bulk alloy data rather than measured powder properties, as discussed in detail within the Introduction section. However, the assumed ability to utilize input parameters from literature data for a bulk material counterpart when determined using the Eulerian algorithm in Abaqus using bulk parameters was definitively shown to underestimate the temperature distribution during impact [55]. As pointed out by Assadi et al., it is possible that this difference could be relevant when considering the bonding mechanism in cold spray. Plastic strain has typically been considered a main factor for bonding in cold spray, and it is similar for the two cases [55]. Given the fact that $A, B$, and $N$ are related to the flow stress, it stands to reason that the measured and calculated yield strengths obtained herein could be analyzed further for the purpose of determining JC parameters from load-depth nanoindentation data.

In addition to the plastic constitutive properties that are dependent upon powder properties, rather than bulk, as shown elsewhere as well as herein via microstructural evaluation and mechanical characterization of the gas-atomized alloy condition versus the cast alloy condition, particle impact simulations could also be enhanced via microstructurally accurate particle rendering within FEA. For example, instead of simply etching and measuring or calculating the given size within a powder particle, electron backscatter diffraction analysis of the cross-sections of a set of particles for a given particle could be utilized for 3D reconstruction, and Abaqus importable synthetically reconstructed volumetric microstructures could be rendered from Dream.3D, for example. Then, such renderings could be confirmed according to sectioning protocols and utilized in FEA of cold spray impact phenomena. As a result, impact modeling would not only capture the unique mechanical behavior of a given powder but also the microstructure, making the simulation that much more proximal to reality. In the meantime, an example set of FEA simulations using microstructure-informed renderings of particulate feedstocks exposed to varied thermal processing parameters are shown in Figures 12 and 13. 


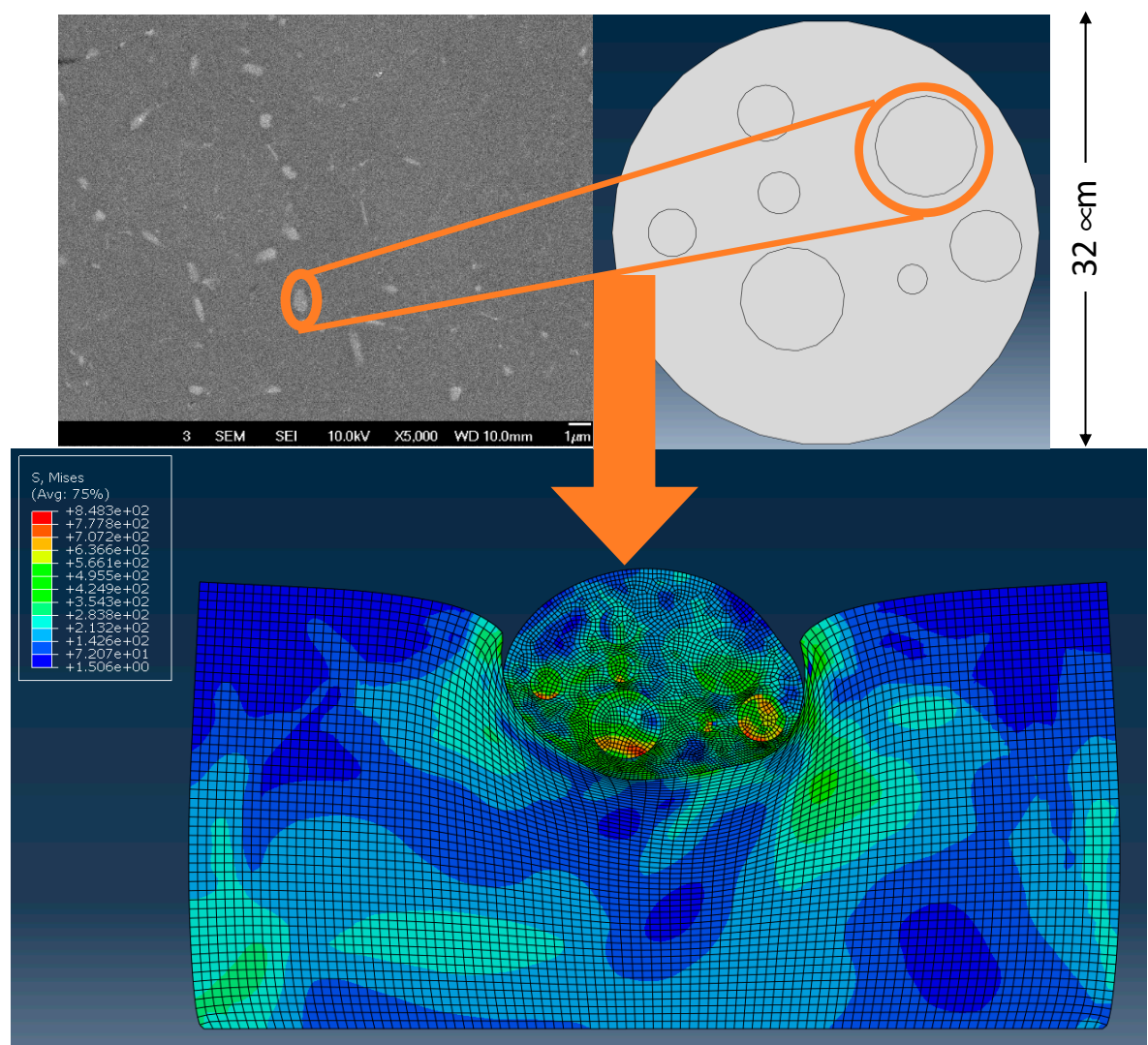

Figure 12. Finite element analysis (FEA) single-particle impact simulation using secondary phases of high hardness.

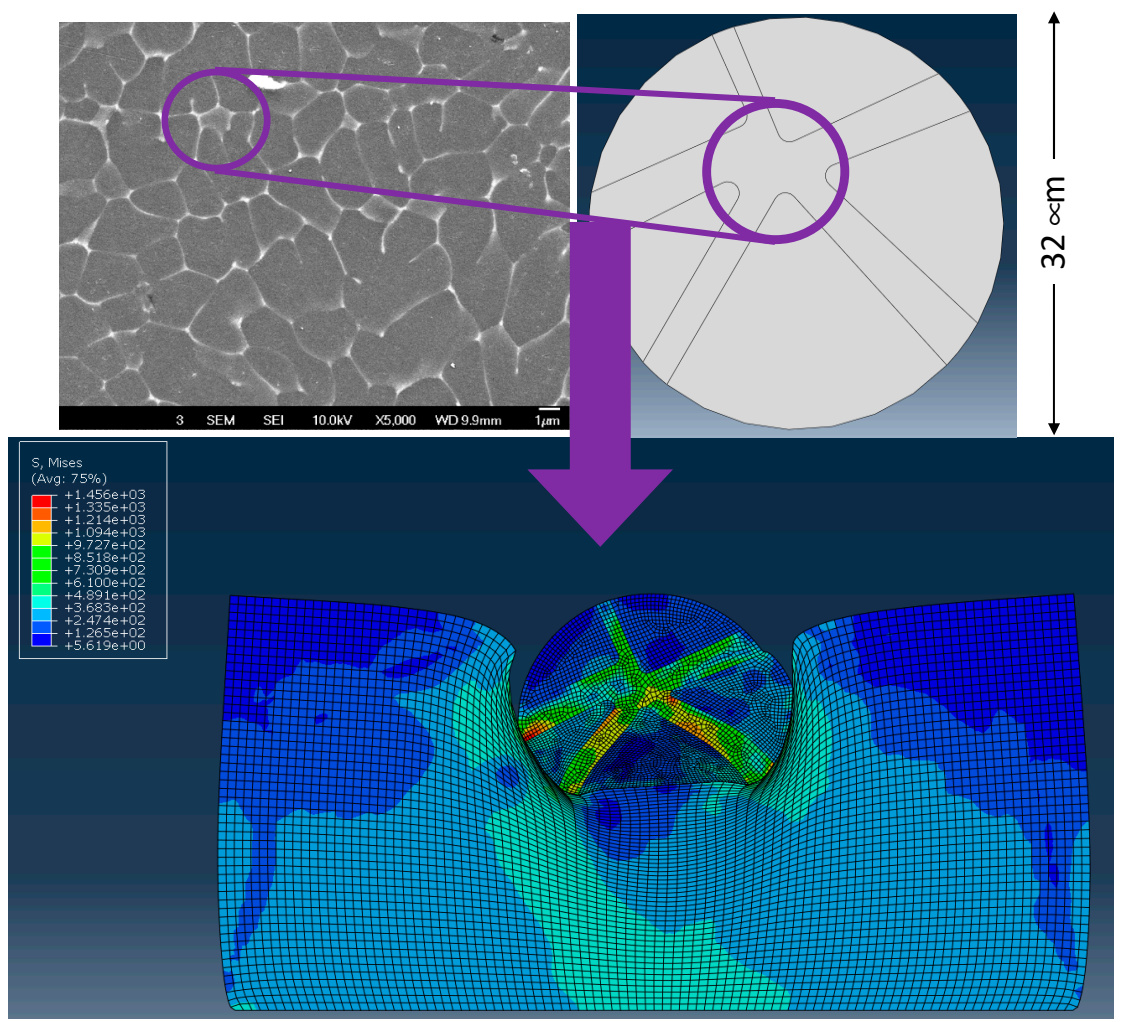

Figure 13. A FEA single particle impact using hard intermetallic network along boundaries. 
Beyond the realm of enhancing particle impact modeling, this provides unequivocal confirmation that gas-atomized alloyed aluminum powders may not be conceptualized, in terms of material properties, as a similar enough material system to their bulk counterparts to determine cold spray processing parameters. Specifically, the essential parameter known as the critical impact velocity $\left(v_{c}\right)$ has historically been formulated as being dependent upon the ultimate tensile strength $\left(\sigma_{U T S}\right)$ of a particle in [56], as shown in, as follows,

$$
v_{c}=\sqrt{\frac{4 F_{1} \sigma_{U T S}\left(1-\frac{T_{i}-T_{R}}{T_{m}-T_{R}}\right)}{\rho}+F_{2} c_{p}\left(T_{m}-T_{i}\right)}
$$

such that

$$
v_{c} \propto \sqrt{\sigma_{U T S}}
$$

Previous research has also established a link between $v_{c}$ and particle diameter. The established link found that the $v_{c}$ increases as the particle diameter decreases. Since our work presented herein demonstrated a direct link between particle diameter and grain size followed by grain size and strength, the above direct relation between $v_{\mathcal{C}}$ and $\sigma_{U T S}$ in terms of particle diameter as well was found to also be consistent with the previously established connection. The consistency between the $v_{\mathcal{C}}$ and $\sigma_{U T S}$ and $v_{c}$ and particle diameter dependency corresponds with the fact that smaller particles will have greater $\sigma_{U T S}$, since their grain sizes are consequently smaller. Being able to use rapid mechanical and microstructural assessment methods for powder particle evaluation will enable more robust and rapid processing parameter optimization and cold spray performance with minimal trial and error. Thus, one may relate $\sigma_{Y S}$ to $\sigma_{U T S}$ in accordance with

$$
\sigma_{U T S} \approx(1.4)\left(\sigma_{Y S}\right)
$$

where $\sigma_{Y S}$ is either obtained from the Tabor relation using the $H_{0}$ nanoindentation-derived value or computed from the Hall-Petch relation.

In addition to the ability to refine the parameters for particle impact modeling as well as the capacity to predict $v_{\mathcal{c}}$ from the mechanical properties and microstructure of a given powder, the kinetics and thermal processing response unique to powders versus their bulk counterpart can assist in the pursuit of achieving strength-toughness synergy in cold spray. This can be done by way of utilizing the thermal processing knowledge obtained herein and building upon it to achieve a sprayable powder that has greater deposition efficiency, enhanced particle-particle bonding, better particle-substrate adhesion, and greater elongation-to-failure. Furthermore, this can be achieved without postprocessing the consolidated material through powder pre-processing prior to cold spray deposition. By way of assessing the transformation kinetics highlighted herein, one may more easily formulate a heat-treatment protocol that maximizes intermetallic precipitate and compound dissolution while minimizing the deleterious coarsening of secondary phases and dispersoids.

The slight grain growth from thermal processing and residual strain relief will certainly enhance the degree of deformation associated with particle impact as well. Nevertheless, the prospective implications put forth within this subsection of the manuscript called upon less recent mechanistic frameworks for particle bonding during cold spray impact phenomena. A more modern and experimentally substantiated and observed $v_{c}$ framework has since been declared in $[57,58]$ in terms of shockwave-mediated hydrodynamics, spall strength, the elastic limit, and the speed of sound as a function of the bulk modulus (which can be expressed as a function of the modulus of elasticity) of a material and the materials density, such that

$$
v_{\mathcal{C}}=\left(\frac{\sqrt{1+\frac{4 s \alpha f(T) g(d)}{k}}-1}{s}\right) \sqrt{\frac{B}{\rho}} \approx \frac{2 \alpha f(T) g(d)}{k} \sqrt{\frac{B}{\rho}}
$$


and

$$
\frac{v_{c}}{C_{o}}=\left(\frac{\sqrt{1+\frac{4 s P_{s}}{k B}}-1}{s}\right) \approx \frac{2}{k}\left(\frac{P_{s}}{B}\right)
$$

\section{Concluding Remarks}

There is but one critical conclusion to be drawn from this study: though the powder and cast conditions of an alloy may have the same compositional chemistry or microstructural denotations, the properties of the two are uniquely different from one another. The uniqueness was largely observed via secondary phase analysis, microstructural grain size measurements and calculations, variation in cooling rates, and the differences in mechanical behaviors. With this in mind, it is important to evaluate powders as their own material and develop thermal treatments specific for this condition, prior to use in cold spray additive manufacturing techniques and cold spray materials consolidation approaches.

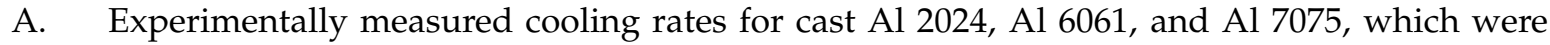
obtained by way of the use of the thermocouples, revealed the fact that the $\mathrm{Al} 6061$ and Al 7075 castings initially achieved greater cooling rates as a function of time versus Al 2024. However, the $\mathrm{Al} \mathrm{2024's} \mathrm{cast} \mathrm{cooling} \mathrm{rate} \mathrm{as} \mathrm{a} \mathrm{function} \mathrm{of} \mathrm{time} \mathrm{was} \mathrm{found} \mathrm{to} \mathrm{eventually} \mathrm{surpass} \mathrm{the}$ values along the cooling rate versus time curves for Al 6061 and Al 7075 castings. Still, Al 7075 achieved the greatest cooling rate during solidification upon casting, followed by $\mathrm{Al} 6061$ and then $\mathrm{Al}$ 2024. Still, $\mathrm{Al} 6061$ reached its maximal casting cooling rate before $\mathrm{Al} \mathrm{7075,} \mathrm{while} \mathrm{both}$ $\mathrm{Al} 6061$ and Al 7075 reached their peak cooling rates before Al 2024. Finally, the difference between the maximum and minimum cooling rates as a function of time for each alloy designation considered herein could be organized from greatest to lowest as follows: $\mathrm{Al} \mathrm{7075,} \mathrm{Al}$ 6061, followed by Al 2024.

B. The cooling rates associated with the gas-atomized powders were ascertained as a function of particle diameter for each of the gas-atomized alloys considered. The calculated cooling rates as a function of particle diameter for each of the gas-atomized systems considered during the course of this work were similar to one another. Gas-atomized Al 6061 was the rapidly solidified alloy with the greatest cooling rate for a given particle size, followed by Al 7075 and $\mathrm{Al} 2024$ in that order.

C. DSC was used to analyze the differences in the formation and dissolution of the various secondary phases. A difference between peak shape, size, and location can be seen between the processing condition of all the alloys studied herein. The fact that $\mathrm{Al} 6061$ powder and wrought samples exhibit similar DSC results while being arguably the most different based on secondary phase area fraction warrants further investigation in subsequent studies.

D. Image analysis of SEM images was performed to quantify the amount of solid solution strengthening; the lower the secondary phase area fraction, the higher the degree of solid solution strengthening. A significant change in the secondary phase area percent of the GA Al 6061 powder occurred upon thermal processing. As shown, the Fe-rich precipitates dissolved upon processing to about $25 \%$ of the as-atomized phase area percent. At the same time, a noteworthy precipitation of Mg-rich phases also occurred upon treating the powder. Regarding the cast samples, little to no change was observed. As presented, the microstructural SDAS sizes of the cast $\mathrm{Al} 6061$ samples, in comparison to the gas-atomized samples, were found to be approximately seven times greater in diameter.

E. Mathematical manipulation of the computed cooling rates and calculated microstructural effective grain sizes enabled the effective grain size as a function of powder particle size to be calculated for $\mathrm{Al} \mathrm{7075,} \mathrm{Al}$ 2024, and $\mathrm{Al}$ 6061. Al 6061's calculated effective grain size as a function of particle size was the most consistent among the experimentally measured findings and observations, followed by Al 2024 and Al 7075 in that order. The Al 7075 calculations 
over-estimated the effective grain size as a function of particle size when compared with the corresponding experimental data. On the other hand, the Al 2024 computed curve trajectory was reasonably consistent with the experimentally measured values until surpassing a particle diameter of approximately $45 \mu \mathrm{m}$. Therefore, future work will be required to determine the optimal model input parameters for gas-atomized Al 2024 and Al 7075 powder.

Author Contributions: Conceptualization, B.C.S. and C.W.; Data curation, C.W.; Formal analysis, B.C.S. and C.W.; Funding acquisition, D.L.C.; Investigation, B.C.S. and C.W.; Methodology, B.C.S. and C.W.; Project administration, B.C.S. and D.L.C.; Supervision, V.K.C.J., A.T.N., R.D.S.J. and D.L.C.; Validation, B.C.S. and C.W.; Visualization, B.C.S. and C.W.; Writing-original draft, B.C.S., C.W. and D.L.C.; Writing-review and editing, B.C.S., C.W., V.K.C.J., A.T.N., R.D.S.J., and D.L.C. All authors have read and agreed to the published version of the manuscript.

Funding: This work was funded by the United States Army Research Laboratory, grant No. \#W911NF-15-2-0024.

Acknowledgments: This work was performed in part using the Helios PFIB at the University of Connecticut/Thermo Fisher Scientific Center for Advanced Microscopy and Materials Analysis. We wish to thank Alino Te for his assistance in using the OES as well as Richard Coffin for his assistance with collecting SEM data. Thanks is also afforded to Carl Soderhjelm, Associate Director of the Advanced Casting Research Center, and Assistant Research Professor of Mechanical Engineering at WPI. Gratitude is also extended to Baillie Haddad for the scanning transmission electron microscopy experimentation, as well as Jeremey M. Schreiber and Timothy Eden at the Applied Research Laboratory at Pennsylvania State University for running the FEA simulations.

Conflicts of Interest: The authors declare no conflict of interest.

\section{References}

1. Huang, X.; Lang, L.; Wang, G.; Alexandrov, S. Effect of Powder Size on Microstructure and Mechanical Properties of 2A12Al Compacts Fabricated by Hot Isostatic Pressing. Adv. Mater. Sci. Eng. 2018, 2018, 1989754. [CrossRef]

2. Heaney, D.F. Handbook of Metal Injection Molding; Woodhead Publishing: Shaston, UK, 2012; ISBN 9780857096234.

3. Qiu, J.W.; Liu, Y.; Liu, Y.B.; Liu, B.; Wang, B.; Ryba, E.; Tang, H.P. Microstructures and mechanical properties of titanium alloy connecting rod made by powder forging process. Mater. Des. 2012, 33, 213-219. [CrossRef]

4. Sun, P.; Fang, Z.Z.; Zhang, Y.; Xia, Y. Review of the Methods for Production of Spherical Ti and Ti Alloy Powder. JOM 2017, 69, 1853-1860. [CrossRef]

5. Vasudevan, A.K.; Doherty, R.D. Aluminum Alloys: Contemporary Research and Applications; Elsevier: Amsterdam, The Netherlands, 1989; ISBN 0123418313.

6. Rokni, M.R.; Widener, C.A.; Crawford, G.A. Microstructural evolution of $7075 \mathrm{Al}$ gas atomized powder and high-pressure cold sprayed deposition. Surf. Coat. Technol. 2014, 251, 254-263. [CrossRef]

7. Sabard, A.; de Villiers Lovelock, H.L.; Hussain, T. Microstructural Evolution in Solution Heat Treatment of Gas-Atomized Al Alloy (7075) Powder for Cold Spray. J. Therm. Spray Technol. 2018, 27, 145-158. [CrossRef]

8. Bryer, C.S.; Caitlin, E.W.; Victor, K.; Champagne, J.; Danielle, L.C. Initial Observation of Grain Orientation Dependent Nanoindentation Hardness of Al 6061 Gas-atomized Powder. Int. J. Metall. Met. Phys. 2020, 5, 050. [CrossRef]

9. Massar, C.; Tsaknopoulos, K.; Sousa, B.C.; Grubbs, J.; Cote, D.L. Heat Treatment of Recycled Battlefield Stainless-Steel Scrap for Cold Spray Applications. JOM 2020, 72, 3080-3089. [CrossRef]

10. Sousa, B.; Sundberg, K.; Massar, C.; Champagne, V.; Cote, D. Spherical Nanomechanical Characterization of Novel Nanocrystalline Cu Cold Spray Manufactured Materials. In Proceedings of the APS March Meeting 2019, Boston, MA, USA, 4-8 March 2019.

11. Champagne, V.; Helfritch, D. Critical Assessment 11: Structural repairs by cold spray. Mater. Sci. Technol. 2015, 31, 627-634. [CrossRef]

12. Champagne, V.K. The Cold Spray Materials Deposition Process; Woodhead Publishing Limited: Southston, UK, 2007; ISBN 978-1-84569-181-3.

13. Champagne, V.; Nardi, A.; Cote, D. Materials characterization of advanced cold-spray aluminum alloys. Int. J. Powder Metall. 2015, 51, 37-47.

14. Belsito, D. Application of Computational Thermodynamic and Solidification Kinetics to Cold Sprayable Powder Alloy Design. Ph.D. Thesis, Worcester Polytechnic Instiute, Worcester, MA, USA, 2014.

15. Vander, V.; Baldwin, W. Metallography and Microstructures Handbook. ASM Int. 2004, 9, 229-310. [CrossRef] 
16. Lee, S.; Saito, Y.; Sakai, T.; Utsunomiya, H. Microstructures and mechanical properties of 6061 aluminum alloy processed by accumulative roll-bonding. Mater. Sci. Eng. A 2002, 325, 228-235. [CrossRef]

17. Tsui, T.Y.; Oliver, W.C.; Pharr, G.M. Influences of stress on the measurement of mechanical properties using nanoindentation: Part I. Experimental studies in an aluminum alloy. J. Mater. Res. 1996, 11, 752-759. [CrossRef]

18. Richardson, M.J.; Charsley, E.L. Chapter 13 Calibration and Standardisation in DSC. In Handbook of Thermal Analysis and Calorimetry; Elsevier Science BV: Amsterdam, The Netherlands, 1998.

19. Klar, E.; Samal, P.K. Powder Metallurgy Stainless Steels: Processing, Microstructure, and Properties. Powder Metall. 2007. [CrossRef]

20. Steenkiste, T.H.V.; Smith, J.R.; Teets, R.E. Aluminum coatings via kinetic spray with relatively large powder particles. Surf. Coat. Technol. 2002, 154, 237-252. [CrossRef]

21. Lyle, J.P.; Cebulak, W.S. Powder metallurgy approach for control of microstructure and properties in high strength aluminum alloys. Metall. Trans. A 1975, 6, 685-699. [CrossRef]

22. He, S.; Liu, Y.; Guo, S. Cooling rate calculation of non-equilibrium aluminum alloy powders prepared by gas atomization. Rare Met. Mater. Eng. 2009, 38, 353-356.

23. Ghoncheh, M.H.; Shabestari, S.G.; Abbasi, M.H. Effect of cooling rate on the microstructure and solidification characteristics of A12024 alloy using computer-aided thermal analysis technique. J. Therm. Anal. Calorim. 2014, 117, 1253-1261. [CrossRef]

24. Tsaknopoulos, K.; Walde, C.; Champagne, V.; Cote, D. Gas-Atomized Al 6061 Powder: Phase Identification and Evolution During Thermal Treatment. JOM 2019, 71, 435-443. [CrossRef]

25. Walde, C.; Tsaknopoulos, K.; Champagne, V.; Cote, D. The Microstructural Evolution of Rapidly Solidified Powder Aluminum 2024 During Thermal Processing. Metallogr. Microstruct. Anal. 2019, 8, 415-425. [CrossRef]

26. Walde, C.; Tsaknopoulos, K.; Champagne, V.; Cote, D. Phase Transformations in Thermally Treated Gas-Atomized Al 7075 Powder. Metallogr. Microstruct. Anal. 2020, 9, 419-427. [CrossRef]

27. Sousa, B.C.; Gleason, M.A.; Haddad, B.; Champagne, V.K.; Nardi, A.T.; Cote, D.L. Nanomechanical Characterization for Cold Spray: From Feedstock to Consolidated Material Properties. Metals 2020, 10, 1195. [CrossRef]

28. ASM International Handbook Committee. Properties and Selection: Nonferrous Alloys and Special-Purpose Materials; ASM International: Materials Park, OH, USA, 1990.

29. Pharr, G.M.; Herbert, E.G.; Gao, Y. The Indentation Size Effect: A Critical Examination of Experimental Observations and Mechanistic Interpretations. Annu. Rev. Mater. Res. 2010, 40, 271-292. [CrossRef]

30. Nix, W.D.; Gao, H. Indentation size effects in crystalline materials: A law for strain gradient plasticity. J. Mech. Phys. Solids 1998, 46, 411-425. [CrossRef]

31. Goldbaum, D. Micromechanical Testing of Cold Sprayed Ti Splats and Coatings. Ph.D. Thesis, McGill University, Montreal, QC, Canada, 2012.

32. Shives, T.; Smith, L. Microindentation Hardness Measurements on Metal Powder Particles. In Microindentation Techniques in Materials Science and Engineering; ASTM International: West Conshohocken, PA, USA, 2008; pp. 243-256.

33. Yan, W.; Pun, C.L.; Wu, Z.; Simon, G.P. Some issues on nanoindentation method to measure the elastic modulus of particles in composites. Compos. Part B Eng. 2011, 42, 2093-2097. [CrossRef]

34. Low, T.F.; Pun, C.L.; Yan, W. Theoretical study on nanoindentation hardness measurement of a particle embedded in a matrix. Philos. Mag. 2015, 95, 1573-1586. [CrossRef]

35. Yan, W.; Pun, C.L.; Simon, G.P. Conditions of applying Oliver-Pharr method to the nanoindentation of particles in composites. Compos. Sci. Technol. 2012, 70, 1147-1152. [CrossRef]

36. Cao, Y.; Duan, P.; Chen, J. Modelling the nanomechanical response of a micro particle-matrix system for nanoindentation tests. Nanotechnology 2016, 27, 195703. [CrossRef] [PubMed]

37. McNally, B. Through-Process Modeling of Aluminum Alloys for Cold Spray: Experimental Characterization and Verification of Models. Ph.D. Thesis, Worcester Polytechnic Institute, Worcester, MA, USA, 2016.

38. Clifford, C.A.; Seah, M.P. Modelling of surface nanoparticle inclusions for nanomechanical measurements by an AFM or nanoindenter: Spatial issues. Nanotechnology 2012, 23, 165704. [CrossRef]

39. Chen, Y.C.; Tsao, C.Y.A.; Yang, S.C.; Hsu, C.C. 6061 aluminum powder making and its thermal and mechanical properties. In Applied Mechanics and Materials; Trans Tech Publications Ltd.: Stafa-Zurich, Switzerland, 2012. 
40. Rokni, M.R.; Widener, C.A.; Ozdemir, O.C.; Crawford, G.A. Microstructure and mechanical properties of cold sprayed $6061 \mathrm{Al}$ in As-sprayed and heat treated condition. Surf. Coat. Technol. 2017, 309, 641-650. [CrossRef]

41. Zielinski, W.; Huang, H.; Gerberich, W.W. Microscopy and microindentation mechanics of single crystal Fe-3 wt.\% Si: Part II. TEM of the indentation plastic zone. J. Mater. Res. 1993, 8, 1300-1310. [CrossRef]

42. Chen, J.; Bull, S.J. On the relationship between plastic zone radius and maximum depth during nanoindentation. Surf. Coat. Technol. 2006, 201, 4289-4293. [CrossRef]

43. Thangaraju, S.; Heilmaier, M.; Murty, B.S.; Vadlamani, S.S. On the estimation of true hall-Petch constants and their role on the superposition law exponent in al alloys. Adv. Eng. Mater. 2012, 14, 892-897. [CrossRef]

44. Choi, Y.; Suresh, S. Nanoindentation of patterned metal lines on a Si substrate. Scr. Mater. 2003, 48, $249-254$. [CrossRef]

45. Sabard, A.; McNutt, P.; Begg, H.; Hussain, T. Cold spray deposition of solution heat treated, artificially aged and naturally aged Al 7075 powder. Surf. Coat. Technol. 2020, 385, 125367. [CrossRef]

46. Liu, T.; Story, W.A.; Brewer, L.N. Effect of Heat Treatment on the Al-Cu Feedstock Powders for Cold Spray Deposition. Metall. Mater. Trans. A 2019, 50, 3373-3387. [CrossRef]

47. Walde, C.; Cote, D.; Champagne, V.; Sisson, R. Characterizing the Effect of Thermal Processing on Feedstock Al Alloy Powder for Additive Manufacturing Applications. J. Mater. Eng. Perform. 2019, 28, 601-610. [CrossRef]

48. Becker, H.; Dopita, M.; Stráská, J.; Málek, P.; Vilémová, M.; Rafaja, D. Microstructure and properties of spark plasma sintered Al-Zn-Mg-Cu alloy. Acta Phys. Pol. A 2015, 128, 602-605. [CrossRef]

49. Molnárová, O.; Málek, P.; Lukáč, F.; Chráska, T. Spark plasma sintering of a gas atomized Al7075 alloy: Microstructure and properties. Materials 2016, 9, 1004. [CrossRef]

50. Gan, Y.; Zhang, D.; Zhang, W.; Li, Y. Effect of cooling rate on microstructure and mechanical properties of squeeze cast Al-Cu-Mg alloy. Int. J. Cast Met. Res. 2015, 28, 50-58. [CrossRef]

51. Mullis, A.M.; Farrell, L.; Cochrane, R.F.; Adkins, N.J. Estimation of Cooling Rates During Close-Coupled Gas Atomization Using Secondary Dendrite Arm Spacing Measurement. Metall. Mater. Trans. B 2013, 44, 992-999. [CrossRef]

52. Xu, Z.; Wang, S.; Wang, H.; Song, H.; Li, S.; Chen, X. Effect of Cooling Rate on Microstructure and Properties of Twin-Roll Casting 6061 Aluminum Alloy Sheet. Metals 2020, 10, 1168. [CrossRef]

53. Dowding, I.; Hassani, M.; Sun, Y.; Veysset, D.; Nelson, K.A.; Schuh, C.A. Particle size effects in metallic microparticle impact-bonding. Acta Mater. 2020, 194, 40-48. [CrossRef]

54. Profizi, P.; Combescure, A.; Ogawa, K. SPH modeling of adhesion in fast dynamics: Application to the Cold Spray process. Comptes Rendus Mécanique 2016, 244, 211-224. [CrossRef]

55. Assadi, H.; Irkhin, I.; Gutzmann, H.; Gärtner, F.; Schulze, M.; Villa Vidaller, M.; Klassen, T. Determination of plastic constitutive properties of microparticles through single particle compression. Adv. Powder Technol. 2015, 26, 1544-1554. [CrossRef]

56. Schmidt, T.; Gärtner, F.; Assadi, H.; Kreye, H. Development of a generalized parameter window for cold spray deposition. Acta Mater. 2006, 54, 729-742. [CrossRef]

57. Hassani-Gangaraj, M.; Veysset, D.; Champagne, V.K.; Nelson, K.A.; Schuh, C.A. Adiabatic shear instability is not necessary for adhesion in cold spray. Acta Mater. 2018, 58, 430-439. [CrossRef]

58. Hassani-Gangaraj, M.; Veysset, D.; Champagne, V.K.; Nelson, K.A.; Schuh, C.A. Response to Comment on Adiabatic shear instability is not necessary for adhesion in cold spray. Scr. Mater. 2019, 162, 515-519. [CrossRef]

Publisher's Note: MDPI stays neutral with regard to jurisdictional claims in published maps and institutional affiliations.

(C) 2020 by the authors. Licensee MDPI, Basel, Switzerland. This article is an open access article distributed under the terms and conditions of the Creative Commons Attribution (CC BY) license (http://creativecommons.org/licenses/by/4.0/). 